\title{
PERDURACIONES Y ROMANIZACIÓN EN HISPANIA A LA LUZ DE LA ARQUEOLOGÍA FUNERARIA: NOTAS PARA UNA DISCUSIÓN
}

\author{
POR \\ MANUEL BENDALA GALÁN \\ Universidad Autónoma de Madrid
}

PALABRAS CLAVE: Arqueología funeraria. Hispania romana. Bética. Romanización. Cultura hispanorromana. Cultura romana provincial. Necrópolis romanas. Carmo.

KEY WORDS: Archaelogy of Death. Roman Spain. Baetica. Romanization. Roman provincial culture. Roman necropolis. Carmo.

\section{RESUMEN}

El artículo aborda una aproximación teórica al concepto historiográfico de «romanización» y su discusión a la luz de las aportaciones de la Arqueología funeraria. Se discuten algunas aportaciones recientes acerca del significado cultural y sociológico de la conocida necrópolis de Carmo, y se vuelve a ella -y a otras de la Bética- para analizar fenómenos de romanización y de autoafirmación étnica.

\section{SUMMARY}

The aim of this paper is a discussion about the historiographycal concept of «Romanization», posed by results of the archaeological evidences in funerary contexts of Roman cemeteries in Baetica. The well known necropolis of ancient Carmo is re-examinated to obtain signs of local etnicity and the progress of the romanization.

Es un honor participar en este volumen especial de $A E s p A$, que alcanza el número 75 , un cómputo que, como para años de vida humana, representa madurez y éxito vital, sobre todo si se mantiene el tono de interés y creatividad propio de esta revista, órgano de difusión científica de un centro de investigación principal para nuestros estudios arqueológicos e históricos y, como es bien notorio, una publicación periódica de primera importancia en la maduración de la Arqueología en España. Como respuesta a los propósitos conmemorativos de los responsables de la revista y al prestigio de la misma he resuelto desarrollar un tema también principal en mi propia biografía científica, que se justifica por tratarse de un asunto clásico y sujeto en la actualidad a una importante polémica: la romanización, analizada aquí fundamentalmente a partir de la sugerencias aportadas por el expresivo campo de la Arqueología funeraria.
Hace años que trato de contribuir — con actividades investigadoras en diversos campos y con iniciativas individuales o acometidas en grupo según la envergadura o el tipo de actividad desarrolladaa un mejor entendimiento del proceso histórico-cultural que vivieron las comunidades hispanas como consecuencia de la conquista y la progresiva integración en el Imperio Romano. Ha sido y es un campo de atención prioritaria el estudio de la estructura territorial y urbana, su situación previa a la llegada de Roma, su importancia para la conquista y la evolución posterior como consecuencia de la progresiva integración en el Imperio. Es una cuestión fundamental que permite situar los fenómenos culturales particularmente considerados en un adecuado marco de referencia, insertar los datos o aspectos puntuales en estructuras que les otorgan su verdadera dimensión, sean esas estructuras las que les corresponden en el tiempo histórico, sean las que reelaboramos ahora como resultado del trabajo científico ${ }^{1}$.

Ha sido otro campo de investigación particularmente atendido el referido a la llamada hoy «Arqueología de la muerte», el seguimiento, en fin, de las manifestaciones funerarias, fundamentalmente por su relevancia como indicador cultural, por su capacidad de proporcionar elementos de referencia de gran valor a la hora de recuperar el carácter de sociedades antiguas, que decantaron precisamente en las acciones funerarias, en sus tumbas y en la ritualidad que acompañaba a la muerte, una parte importantísima de su manera de entenderse y proyec-

1 Fue para nosotros un hito, con notable influencia también en los medios científicos generales, el trabajo presentado en el Coloquio celebrado en la Casa de Velázquez de Madrid, en 1986, sobre Los asentamientos ibéricos ante la romanización (Bendala, Fernández Ochoa, Fuentes y Abad, 1987), precedido de algunos en la misma dirección (por ejemplo: Bendala, 1981) y seguido de muchos otros aplicados a desentrañar las realidades urbanas y urbanísticas antes y después de la conquista romana y a sondear en los procesos de perduración y en las fórmulas de cambio en las estructuras territoriales y en las expresiones urbanísticas del progresivamente triunfante modelo de la ciudad romana (entre otros: Bendala, 1989, 1990, 1998, 2002b). 
tarse ante propios y ajenos ${ }^{2}$. Es una virtualidad científica ampliamente desarrollada hoy día ${ }^{3}$, que complementa y matiza la información obtenible en otros ámbitos de la cultura material tratados igualmente por la Arqueología, como los centros de hábitat de las ciudades, o la aportada por otras fuentes históricas, como las literarias o las epigráficas.

En la urbe y en las necrópolis, escenarios principales de la vida y la muerte de las sociedades urbanas, que se configuran en función de una diferenciada «vitalidad» según culturas y épocas, se obtienen claves esenciales para ver y entender adecuadamente los fenómenos culturales y la evolución de las sociedades afectadas por los complejos procesos de perduración y de cambio que determinó el hecho trascendental de la conquista romana. Nuestra ya larga tradición científica en esta materia, ha adoptado por concepto referencial permanente, tanto como punto de partida en la elaboración de hipótesis o de presupuestos analíticos, como en la determinación o la exposición de los resultados, el fenómeno de la «romanización»: el grado de romanización de tal o cual comunidad, su aceptación o la «resistencia» a los cambios «impuestos» por los nuevos dominadores o derivados de la incorporación al Imperio; las circunstancias que la facilitaron o que la estorbaron o frenaron.

No soy, sin embargo, el primero en percibir que tal vez sea una de las maneras menos convenientes de comprender las sociedades y las culturas afectadas por la conquista y la incorporación al Imperio Romano, analizarlas en función de la romanización, un referente equívoco y perturbador ${ }^{4}$, sobre todo en la medida en que sé ha convertido - lo hemos con-

${ }^{2}$ En un trabajo de reciente publicación (Bendala, 2002a) trato con cierta amplitud de tradiciones funerarias ibéricas, materializadas en algunas de las más importantes manifestaciones escultóricas propias de nuestra civilización protohistórica (desde las esculturas de Obulco, a las de Urso/Osuna), en las que puede percibirse el peso de las tradiciones locales y la incorporación a una trayectoria cultural marcada también por la romanización, entre otras cosas por el uso del prestigiado lenguaje artístico de los dominadores romanos. Al trabajo remito para esta cuestión, relacionada con la rtansición entre la etapa ibérica y la romana, sin alargar el contenido de estas páginas.

${ }^{3}$ Ha generado una ya casi ingente literatura científica, de la que destacaría, para una aproximación global a la cuestión: Chapman et alii (ed.), 1981; Morris, 1992; Vaquerizo (ed.), 1991; Blánquez y Antona (ed.), 1992; Fábregas et alii (ed.), 1995.

${ }^{4}$ Sir Ronald Syme lo consideró «ugly and vulgar» (1983, 64), inapropiado como término referible a una política deliberada de «romanización» tan cuestionable que resulta desaconsejable su uso, una advertencia recordada después en numerosas ocasiones (p.e., por su compatriota Keay, 2001, 122). A lo inapropiado y equívoco del término -y del concepto - tuve ya ocasión de referirme en mi estudio de 1981 (35 y passim). vertido, dicho con mayor propiedad-, por la fuerza de las inercias científicas, en parámetro universal e inevitable, protagonista historiográfico casi absoluto de cualquier fenómeno propio de la historia y la cultura del Imperio Romano, especialmente, claro es, cuando se hace la historia de las provincias, como ocurre con las hispanas que directamente nos ocupan. Puede decirse, con algo de simplismo o de exageración, que llevamos siglos tratando de ver y de demostrar cómo Roma forjó su Imperio y lo cimentó en un proceso de transformación y unificación etiquetado como «romanización».

Hace tiempo que se hizo sentir la necesidad de prestar atención a lo que Roma no cambió, a lo que no fue fruto de la romanización, incluso a lo que Roma recibió o asimiló para dar forma a su propio cuerpo cultural, algo que se acepta globalmente en relación con Grecia y la cultura griega, pero que es extensible a otras culturas, empezando por la de sus máximos rivales, los púnicos, en la lucha por el dominio universal. Cuajó, por fortuna, la conclusión de que la evolución sólo podía entenderse y explicarse como resultado de un proceso de síntesis, pero el protagonismo de la romanización, con una fuerte carga exclusivista y de acción unilateral, seguía y sigue pesando en una tradición científica fuertemente condicionada por la asociación de la romanización a los conceptos de aculturación desarrollados fundamentalmente en relación con los fenómenos coloniales y con la política imperialista del siglo XIX y los comienzos del xx.

Así lo subraya en un libro reciente S. Jones (1997, 33), donde analiza la concepción de la romanización y cómo el paso de la época prerromana a la romana en las provincias occidentales del Imperio aparece en la tradición historiográfica como un hecho constituyente de una frontera temporal, que enfatiza el paso de sociedades no literarias a literarias, y separa dos períodos sustancialmente distintos, al tiempo que creaba una fisura entre las tradiciones científicas de la Prehistoria y la Arqueología clásica (ver también: Cunliffe, 1988). En las reconstrucciones históricas tradicionales, el análisis de la cultura y la identidad a partir de la conquista romana se resolvía en términos de una frontera temporal entre las amplias categorías culturales de «nativo» (o «indígena», como es más usual en la literatura científica española) y «romano», de modo que el contacto entre Roma y las sociedades indígenas tras la conquista es asumido como iniciador de un breve período de cambio, que conduciría a una síntesis cultural y social según un proceso caracterizado como de «romanización»(Jones, 1997, 29-33).

La frontera creada entre las culturas del Hierro y 
la época romana forjó una rígida armadura en las estructuración de las interpretaciones de las identidades culturales afectadas por la conquista y la integración en el Imperio, un estado de cosas que había que romper prestando la debida atención a los fenómenos de interacción, a la persistencia y la transformación de las estructuras políticas y socioeconómicas, y encuadrando los fenómenos afectos a la conquista romana y la romanización en marcos teóricos que pudieran proyectarse a la realidad histórica sin forzarla con presupuestos inadecuados. A ello se ha aplicado con variado éxito la investigación de los últimos años, en lo que he pretendido contribuir personalmente para el caso de las provincias hispanas con reflexiones generales o análisis de aspectos culturales específicos, que han incidido fundamentalmente en la necesidad de reconocer la importancia de las sintonías culturales existentes entre conquistadores y conquistados, de la incorporación previa de sectores determinantes de Hispania - particularmente los sujetos a la dominación púnica y al proyecto político de los Barca- a la misma corriente helenística que empujaría la acción de Roma ${ }^{5}$, o el reconocimiento de procesos tras la conquista insertos en una dinámica sólo entendible en clave de continuidad con la anterior ${ }^{6}$.

En este empeño se alinean tantos trabajos recientes, con distintas opciones conceptuales y metodológicas según autores o escuelas, que es imposible - tanto como innecesario aquí- citarlos y comentarlos por extenso ${ }^{7}$. Pero cuantos conozcan más o menos de cerca la discusión científica, y más los directamente participantes en ella, estarán de acuerdo en que buena parte del esfuerzo intelectual tiene que ir dirigido a desembarazarse del peso de concepcio-

5 Un asunto de primera importancia que me ocupó ya en un trabajo de planteamientos y expresiones deliberadamente heterodoxos para su momento (Bendala, 1981), que significativamente abordaba la romanización como aspecto a considerar en las etapas más recientes de la cultura ibérica, la «baja época».

${ }^{6}$ Subrayé ampliamente los fenómenos de.continuidad en la dinámica interna y externa que experimentaron las culturas hispanas antes y después de la conquista romana en mi trabajo de 1987, cuestiones que, como la sintonía previa, han sido muy tenidos en cuenta igualmente por otros investigadores, como, por ejemplo, C. González Román (1994, 134 y passim), compartiendo para la Bética mis argumentaciones, o C. Haselgrove (1984 y 1990), con amplio soporte teórico, para el caso de la Galia belga.

7 Me limito a recordar dos amplios trabajos, muy conocidos, de hispanistas extranjeros - Keay, 1992; Fear, 1996-, con análisis alineables en la citada renovación conceptual, con los que comparto ideas y propuestas - aparte de otras que no es el caso discutir o puntualizar ahora-, del tipo de las propuestas en mi trabajo de 1987. En la misma línea, con amplia argumentación y numerosas referencias, se sitúa un trabajo de reciente publicación de S. Keay, 2001. nes que gravitan sobre el estado actual de la investigación; a retomar, a menudo, argumentaciones ya propuestas para hacer frente a ideas que se creían superadas en el actual status quaestionis ${ }^{8}$. Y una de ellas es precisamente el entendimiento simplista y unilateral de la «romanización» como término aplicado a la globalidad del proceso cultural experimentado por las sociedades integradas en el Imperio. La paradoja, en relación con lo que se ha dicho pocos párrafos más arriba, o la perversión epistemológica - si se quiere-, radica en denominar un proceso de síntesis con la apelación exclusiva a uno de sus actuantes o componentes, algo más grave o más cargado de consecuencias de lo que suele creerse o percibirse, si de lo que se trata es de construir un discurso científico capaz de reproducir las situaciones y procesos de la realidad sin elementos distorsionadores.

El pensamiento y la ciencia discurren en función de leyes internas que los condicionan, se sea consciente o no de ello. La romanización es un hecho importantísimo e incuestionable, pero tal y como se ha configurado en nuestra tradición científica, conviene replantearla radicalmente si queremos innovar nuestras disciplinas, si consideramos necesario depurarlas de sus ingredientes menos apropiados o convenientes. Desde la convicción de que se hacía preciso dar un giro innovador - como viene haciéndose- a las actitudes científicas que tratan de recuperar más auténticamente las culturas hispanas en época romana, resultan sugerentes algunas reflexiones expuestas por Eugenio Trías en un libro de reciente publicación (Trías, 2001). Parte el filósofo de una fecunda idea de la «Ciudad» como metáfora del Cosmos: la creación humana e intelectual que asimila, absorbe y recrea la naturaleza; cada cultura y cada miembro de la sociedad que la sustenta contribuye a construirla o a deconstruirla; cada uno edifica o crea su Cosmos particular, su Ciudad propia (Trías, 2001, 14-15).

Roma - recuerdo por mi lado, antes de volver a lo que me interesa de Trías - es paradigmática como ejemplo de civilización que acabaría por sentirse a sí misma como proyección universal de un cosmos ordenado, perfectamente anclado en sus sistemas socioeconómicos y políticos, en su acervo científico y técnico. Lideró un determinado orden cultural - fuera del cual se hallaba el mundo bárbaro e inferior de las externae gentes-, obtenido mediante la extensión de ideas y fórmulas culturales propias o amasadas y personalizadas en su seno, fe-

${ }^{8}$ Un ejemplo, en los argumentos contenidos en el trabajo de Fernández Ochoa y Morillo, 2002, con propuestas de interés para un más correcto entendimiento de la romanización de Hispania, particularmente de sus ámbitos septentrionales. 
nómeno que puede denominarse cabalmente de romanización; pero también por la incorporación, la absorción o la validación de realidades o contenidos de las otras sociedades y culturas integradas en el Imperio, que dieron al mismo su extraordinaria variedad y complejidad.

Explicar todo el Imperio y la historia de cada una de sus provincias a la manera de un proceso unilateral de unificación cultural con referencia a los modelos romanos, que es en lo que consiste observar las provincias a través del prisma de la romanización, implica orillar aspectos esenciales de la historia y la cultura consideradas, ingredientes no romanos que pudieron ser mucho tiempo esenciales para los contenidos y los procesos culturales que bulleron en el seno del Imperio y partícipes importantes de la síntesis final de la cultura de cada región o cada provincia (de lo que llamamos, más o menos apropiadamente, galorromano, hispanorromano, grecorromano, etc.). Qué duda cabe de que el peso y el poder de Roma tuvieron un protagonismo esencial en el proceso, y que el resultado fue una creciente homogeneización cultural en función de los modelos romanos. Pero la homogeneización no fue ni rápida ni total, como es bien sabido, y no conviene olvidar que buena parte del caudal cultural romano venía de aguas aportadas por otros, que Roma hizo suyas. Si seguían inundando las tierras de siempre, ahora con el beneplácito de Roma o pese a ella, ¿cabe llamar a ese hecho romanización?

Para el caso de Hispania, durante mucho tiempo -y todavía hoy - se advierte una investigación particularmente preocupada por sondear los mecanismos de la romanización y su supuesto triunfo, a menudo exaltado como un logro o un éxito para determinada región o ciudad, fundiéndose, en la demostración del «triunfo», la idea de un logro del pasado y de un objetivo considerado como óptimo para la propia investigación ${ }^{9}$.

\footnotetext{
${ }^{9}$ Suele ser una posición inconsciente derivada de las mencionadas concepciones coloniales, según las cuales la romanización se entiende como incorporación a las formas de progreso, alcanzadas por los colonizados por esa vía, apartándose del mundo bárbaro para integrarse en el civilizado. Es, además, resultado de la posición habitual desde la que observa el historiador a partir de la conquista en función de las fuentes disponibles, como subrayaba hace unos años, con argumentos que se me permitirá reproducir: «El enfoque cultural de la época en función de la romanización es una posición historiográfica explicable por varias razones, fundamentalmente dos: la propia potencia cultural de Roma y la posición desde la que habitualmente observa el historiador. Esta última razón es fácilmente explicable: a diferencia de los análisis internos que se realizan para el estudio de nuestras culturas prehistóricas, el punto de vista se va desplazando algo al exterior en los tiempos protohistóricos, y se sitúa decididamente fuera desde que Roma pone pie en Hispania. Desde entonces el punto de
}

Pero se ha ido imponiendo la necesidad también de prestar la atención que merecían las otras realidades que no eran fruto de la romanización y con ella convivieron dando color, variedad y cuerpo al Imperio ${ }^{10}$. Frente a la romanización como proceso de homogeneización o unificación cultural, había que buscar y valorar las diferencias. Es la necesidad que, para sus planteamientos, subraya Trías — de ahí la evocación de su obra iniciada más arriba- cuando escribe, que «las equiparaciones nos sumergen en lo más obtuso de todo logro: aquél que se contenta con la vacía igualdad, o con ese 'centro insustancial' del espacio lógico que es, para Wittgenstein, la Identidad, en lugar de porfiar por lo que exige riesgo, reflexión y tensión intelectual: la producción de las verdaderas diferencias» (Trías, 2001, 22-23).

Quedémonos, no con la radicalidad del lenguaje, que no pretendo trasladar a nuestros encuentros o desencuentros deliberativos, sí con lo sustancial de un planteamiento que ilumina los propios, también cuando añade que toda innovación en filosofía consiste en desplazar el centro de gravedad de los conceptos principales que la componen, o en trasladar al centro algún concepto que suele hallarse muchas veces en la periferia de las ideas que prevalecen en todo sistema o cuerpo científico. Es lo que muchas veces he pretendido - como otros- al desplazar del centro de atención de la investigación a la romanización y situar en él las llamadas «pervivencias», descargándolas de sus significantes menos apropiados (los de «residualidad» o «extemporaneidad») y devolviéndoles sus verdaderos valores, para lo que puede resultar más adecuado el término de perduraciones. «La piedra desechada» - y vuelvo a citar, para acabar, de nuevo a Trías- «será convertida en piedra angular» ${ }^{11}$.

observación principal está al lado del romano, apoyado en las únicas fuentes históricas de que se dispone... Consciente o inconscientemente, el historiador 'acompaña' a la principal protagonista de entonces - Roma- y observa las culturas autóctonas como un escenario de fondo, a veces como un lastre que frena o retrasa el papel que aquella protagonista presuntamente desempeña: la romanización» (Bendala, 1987, 569-570; donde se desarrollan más por extenso estas ideas, en un discurso que en parte actualizaría o corregiría, y en una parte sustantiva mantendría ahora).

${ }^{10}$ Entendiendo la romanización como una extensión progresiva de la civitas romana, y que ésta tiene fundamentalmente carácter sociojurídico, esos ingredientes del Imperio no derivados de la directa traslación de las fórmulas culturales y jurídicas romanas están estudiándose modernamente bajo el concepto de la «no ciudad» (también equívoco, por otra parte), que se refiere en buena medida a la subsistencia de la realidad prerromana en el seno del Imperio. Véase, últimamente, González Román, 2002.

11 Trías, 2001, 26. Sobre la concepción de las «pervivencias» hispanas en discursos históricos que gravitan en torno a la romanización, véanse mis observaciones de 1987, 570571 y passim. 
Voy extendiéndome ya demasiado en los preliminares de un artículo que se saldría de sus objetivos si pretendiera redondear el concepto de romanización y su compatibilización con perduraciones de tradiciones y realidades culturales locales, que convivieron más o menos tiempo en la Hispania romana o en la Bética, como en el resto del Imperio. Sólo subrayaré que, en cualquier caso, y sea cual sea el momento que elijamos, la romanización ha de ser entendida como ingrediente dinámico de realidades socioeconómicas y culturales híbridas, polifacéticas o poliestratificadas, en las que conviven elementos de naturaleza distinta, que experimentan procesos con connotaciones y ritmos también distintos. Habrá elementos romanos o itálicos y no romanos, que interaccionan entre unas comunidades y otras y en el seno de una misma comunidad, una complejidad de colores y planos trasladables a los individuos mismos, que pueden ser percibidos también como metáforas vivas de la complejidad y diversidad de la cultura a la que pertenecen.

A estas sociedades tan complejas y poliédricas, lo que no les conviene son juicios que hacen suponer una realidad desarticulada, simple y unitaria, que es lo que, se quiera o no, expresan juicios tales como «tal comunidad estaba totalmente romanizada». Confieso no saber, en ocasiones, qué se quiere decir exactamente con pronunciamientos en tales términos. Que cuando se emplean, tanto por autores antiguos como modernos, obligan inmediatamente a entrar a analizar las razones subyacentes a un juicio que, en principio, puede contribuir más a confundir que a aclarar las cosas.

Es lo que ocurre con èl conocido pasaje de Estrabón 3,2,15 acerca de la Bética: «los turdetanos, en particular los que habitan en las proximidades del Betis, se han asimilado perfectamente al modo de vida de los romanos y ni siquiera se acuerdan ya de su propia lengua. La mayoría se han convertido en latinos y han recibido colonos romanos, de modo que poco les falta para ser todos romanos» ${ }^{12}$. $\mathrm{Ha}$ sido repetidamente usado como supuesta prueba de que la Bética estaba, en época de Augusto, completamente romanizada, en el sentido de que había cambiado totalmente su cultura por la romana. Pero es una cuestión ya muy debatida y asumida que el juicio de Estrabón no puede ser aceptado al pie de la letra, sino leído con cautela y relativizado por muchas razones ${ }^{13}$, como a este específico caso subrayó hace tiempo García y Bellido (1967).

12 He tomado la traducción reciente de J. Meana y F. Piñero, de Biblioteca Clásica Gredos, 169, Madrid, 1992, 74.

${ }_{13}$ Las motivaciones ideológicas que determinan los contenidos del textos estraboniano, en el marco del programa po-
La primera parte de la cita hace referencia a una romanización cultural - programada o no, impulsada desde fuera o desde dentro- que tenía efectos evidentes en la Bética, subrayada y exagerada por Estrabón por intereses políticos e ideológicos. Pero conviene recordar que en buena parte se pondera una asimilación que venía facilitada por la propia tradición cívica de los turdetanos, poseedores de una vieja politeía que el mismo Estrabón enaltece en otros lugares de su obra $(3,1,6)$ y que los estudios arqueológicos e históricos han venido a demostrar últimamente ${ }^{14}$. Esa vieja tradición urbana y su puesta al día por la incorporación a la oleada helenística explicaría una asimilación a Roma - a sus «formas de vida» urbanas - por proximidad y no por transformación, aunque también la hubiera y estuviera facilitada por esa sintonía básica de partida, como el mismo García y Bellido $(1967,12)$ tuvo el acierto de señalar. Una de sus expresiones más importantes hubo de ser el triunfo del latín como lengua vehicular y de prestigio; también, bastante pronto, lengua de expresión de la vida pública y oficial. Pero no hubo de ser tan rápido el olvido de las lenguas vernáculas, ni en las grandes ciudades, donde la penetración del latín hubo de producirse más veloz y profundamente, y mucho menos en las ciudades menores y en los medios rurales, donde mucho tiempo hubieron de perdurar las lenguas propias y, en todos los casos, mantenerse un bilingüismo de compromiso ${ }^{15}$ que se convertiría en expresión privilegiada del mestizaje cultural que vivirían, entre otros, los turdetanos de referencia. El resto del pasaje alude a categorías jurídicas, no culturales, resultado de una aceleración del proceso de incorporación de individuos y comunidades hispanos a los privilegios de la ciudadanía latina, la intensificación de la colonización como consecuencia de los acontecimientos vinculados a la guerra civil y su desenlace, primero con César y después con Augusto, y la previsión de una extensión de la ciudadanía romana que aún se tomaría su tiempo. Pero apenas hace falta insistir en

lítico de Augusto, han sido señaladas en numerosas ocasiones (p.e., Plácido, 1987-88, Arce, 1989).

${ }_{14} \mathrm{He}$ tratado de la cuestión ampliamente en: Bendala, 1989, 1999 y otros trabajos.

15 De nuevo una expresión ofrecida por García y Bellido en su trabajo sobre la latinización $(1967,13)$, con datos sobre el mantenimiento de las lenguas vernáculas espigables en varios tipos de registros, entre ellos los arqueológicos, como los grafitos sobre recipientes que demuestran un prolongado uso de las lenguas propias. Lo subraya, por ejemplo, acerca ciudades del mediodía hispano y de ámbito fenicio López Castro en trabajos recientes, con datos sobre grafitos y sobre el interesante fenómeno del mantenimiento de la antroponimia fenicia, directamente o traducida al latín (López Castro, 1995, 216-219; 2002, 254-262), otra muestra de hibridismo cultural. 
que se está aludiendo a una «romanización» jurídica que no tiene por qué ir acompañada de cambios culturales, aunque paulatinamente, y con ritmos y casuística propios, también se fueran dando ${ }^{16}$, más aceleradamente desde fines de la República y la implantación del Principado.

En la recuperación del sustancial hibridismo cultural de las comunidades provinciales es donde adquiere su particular relevancia la Arqueología funeraria, uno de los vehículos más eficaces a la hora de acercarnos a rasgos de identidad étnica y cultural, a las diferencias de que hablaba que daban diversidad al gran mosaico cultural del Imperio.

Las tradiciones funerarias no son estáticas ni inamovibles, pero tienen, entre otras cosas por eso mismo, un gran valor como referencia acerca de la identidad de los pueblos y las culturas que las informan, practican y mantienen ${ }^{17}$. No remiten al pasado o sólo al pasado como trasfondo inamovible de una tradición supuestamente irrenunciable, aunque pertenecen a un campo de la cultura particularmente conservador, afecto a las mores antiquae. La relación de las tradiciones funerarias con la etnicidad ${ }^{18}$ (la autodefinición o autoadscripción de una comunidad o un grupo humano) cobra nuevos valores en función de propuestas como las desarrolladas por la Arqueología procesual. En su seno se lleva a cabo una reconceptualización de la etnicidad como un aspecto de la organización social, de las relaciones políticas y económicas, en particular de la competición intergrupal. La identidad étnica — como formula la cuestión S. Jones $(1997,28)$ - implica un mantenimiento activo de fronteras en el proceso de interacción social, măs allá del mero reflejo pasivo de normas culturales. La etnicidad se convierte en

${ }_{16}$ Tal y como se configuran en la investigación actual, la presencia de colonias latinas desde muy pronto, con su carácter de ciudades abiertas y generalmente mestizas - en la que convivían comunidades nativas y coloniales-, constituían puntos de encuentro del conjunto de la población y, particularmente efectivos, entre las élites antiguas y nuevas que marcaban las pautas culturales, con lo que se convirtieron en focos de romanización cultural. No fueron muchas, con el único caso seguro y excepcional por su precocidad de Carteia, a la que pueden añadirse ciudades que pudieron adquirir también ese carácter, como Castulo, Corduba, Iliturgi y seguramente otras (puede verse el trabajo último de Marín Díaz, 2002). Nuestras investigaciones en Carteia permiten comprobar la continuidad urbana y urbanística de la ciudad sin cambios perceptibles hasta mucho después de la conversión en colonia latina en el 171 a.C.; así como una remodelación importante a partir de fines del siglo II o comienzos del i a.C., en que se edificó el grandioso templo de los prótomos de toro, construido en el mismo sitio de un lugar de culto de la ciudad púnica, y tal vez con una advocación que pudo ser la misma o una interpretatio de la divinidad venerada antes (cf.: Bendala et alii, 1994; Roldán et alii, 1999; Blánquez et alii, 2002) un activo del sistema social en perpetua recreación, en contraposición a su previa consideración como un pasivo recordatorio normativo.

Una de sus formas de expresión pueden ser las tradiciones funerarias, cuyo vigor, en su perduración $o$ en sus replanteamientos o redefiniciones, puede ser juzgado teniendo en cuenta, entre otras cosas, la correlación entre afirmación ciudadana y etnicidad ${ }^{19}$. Para el caso de la Betica y de sus tradiciones funerarias -ámbito al que limitaré la elección de unos cuantos ejemplos para apoyo argumental-, sus manifestaciones más importantes constituyen un campo espléndido en el que comprobar procesos de romanización, pero también de autoafirmación como «no romanos», consecuencia, entre otros factores, de su antigua y asentada politeía, de una tradición urbana que permitió una fácil y rápida integración en el Imperio (cosa distinta - permítaseme la insistencia- a la «romanización», que es como suele erróneamente denominarse a ese fenómeno sociológico).

Esta autoafirmación ciudadana, que por contraposición puede aludirse en sentido negativo como «no romana» ${ }^{20}$, es lo que subrayé a mediados de los pasados setenta a propósito de la necrópolis «romana» de Carmo (Bendala, 1976). Sus rasgos formales mayoritarios y sus expresiones rituales mostraban, en pleno siglo i d.C., el afloramiento de una personalidad colectiva que remitía al sustrato púnico o turdetano/púnico de la ciudad, o que brotaba de él, en un gesto de etnicidad activa ${ }^{21}$. Así parecen de-

17 Dicho sea sin entrar del todo en la complejidad teórica que la Arqueología reciente ha ido elaborando en torno a las virtualidades científicas del registro funerario. Un par de comentarios aproximativos, en: Ruíz Zapatero y Chapa Brunet, 1990; Vicent, 1995.

18 Una reflexión en torno a esta problemática específica en relación con las necrópolis de época romano-republicana del Mediodía español: Jiménez Díez, 2002.

${ }_{19}$ La ciudad, sobre todo en la Antigüedad, debió de constituirse en un ámbito privilegiado para los fenómenos de afirmación étnica, al serle consustanciales los mecanismos de cohesión social, de identificación colectiva por parte del grupo humano en que la ciudad consiste. El vigor de las tradiciones urbanas, de lo que entendemos por personalidad ciudadana - casi siempre proyectadas en tenaces persistencias, a menudo asombrosas-, tienen que ver con los mecanismos de etnicidad activa y autoadscripción colectiva de que estamos hablando.

${ }^{20}$ En parecidos términos al de «no ciudad» comentado en la nota 8, expresión, no de aversión, sino emanación espontánea o deliberada de una diversidad tenida como referente de lo propio.

21 Al comienzo de la dominación romana -en el 197 a.C.- participó Carmo en una sublevación contra Roma encabezada por los regulos Culchas y Luxinio, que aglutinó, como cuenta Livio $(33,21,6)$, a otras ciudades del mediodía hispano (Bardo, Malaca, Sexi y ciudades de la Beturia), en un movimiento que, por los ambientes a los que afectó, parece claro que tenía raigambre púnica (cf.: Bendala, 1994 63 ). Fue, pues, un rotundo gesto de autoafirmación colectiva 


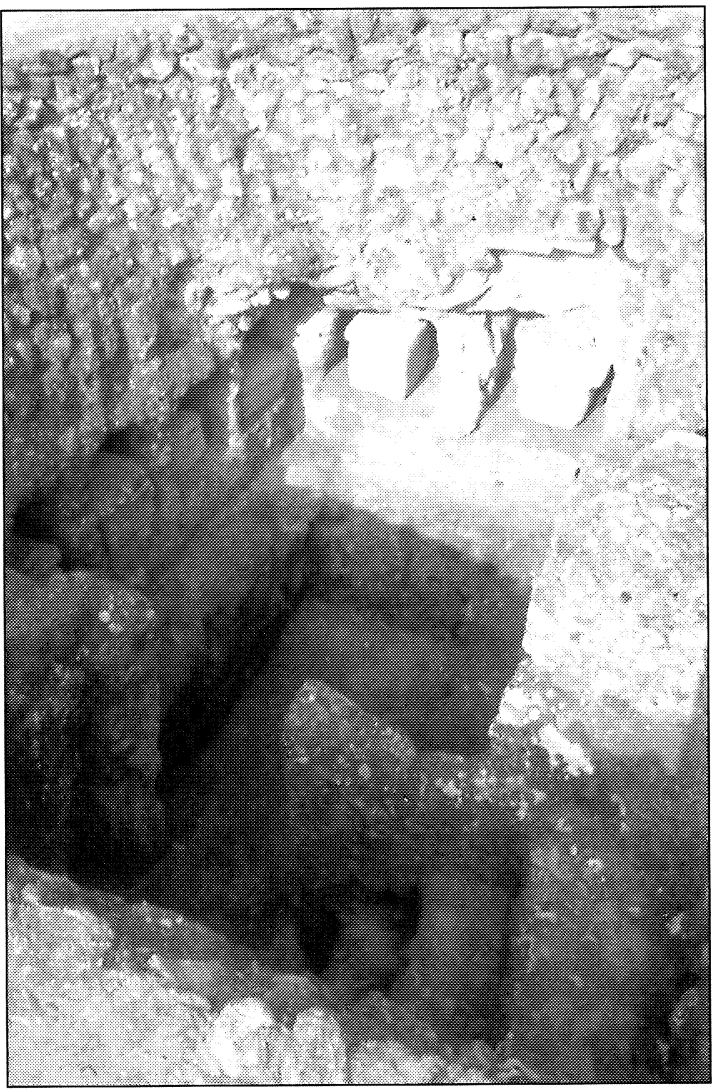

Fig. 1. Vista de una tumba de cámara de la necrópolis occidental de Carmo (Carmona, Sevilla), desprovista de la cubierta. Fot. M. Bendala.

mostrarlo la tipología general de las tumbas (fundamentalmente cámaras excavadas en la roca accesibles mediante pozos o pozos/escaleras: figs. $1 \mathrm{y}$ 2) ${ }^{22}$, la ritualidad reconocible en ellas - con rasgos

frente a Roma que pudo ir acompañado, en el orden cultural, de gestos en el mismo sentido autoafirmativo, entendible en ciudades de acusada personalidad por tensiones habituales intergrupales o políticas en la dinámica colonial. De la duración de esos impulsos o de la permanencia en el tiempo podrá argumentarse lo que resulte apropiado a partir de los datos disponibles, aportados, entre otras cosas, por la rica y personal Arqueología carmonense (una importante puesta al día de la misma para la época romana, donde pueden observarse multitud de facetas relacionadas con el proceso de romanización material y cultural de la ciudad, y de su apego a tradiciones propias - en la religiosidad, las costumbres funerarias y otros aspectos-, se tiene en las Actas recién editadas de un congreso sobre la Carmona romana: Caballos (ed.), 2001 .

${ }^{22}$ Hallazgos recientes o antiguos recuperados por la moderna investigación siguen aportando datos sobre la importancia del sustrato cartaginés en Andalucía, entre los que destaco ahora la valoración de una tumba de cámara de tipo de las carmonenses, a la que se accedía por un profundo pozo de unos doce metros, hallada a comienzos de siglo en tierras de Marchena, en las cercanías de Carmona, que ha sido aso-
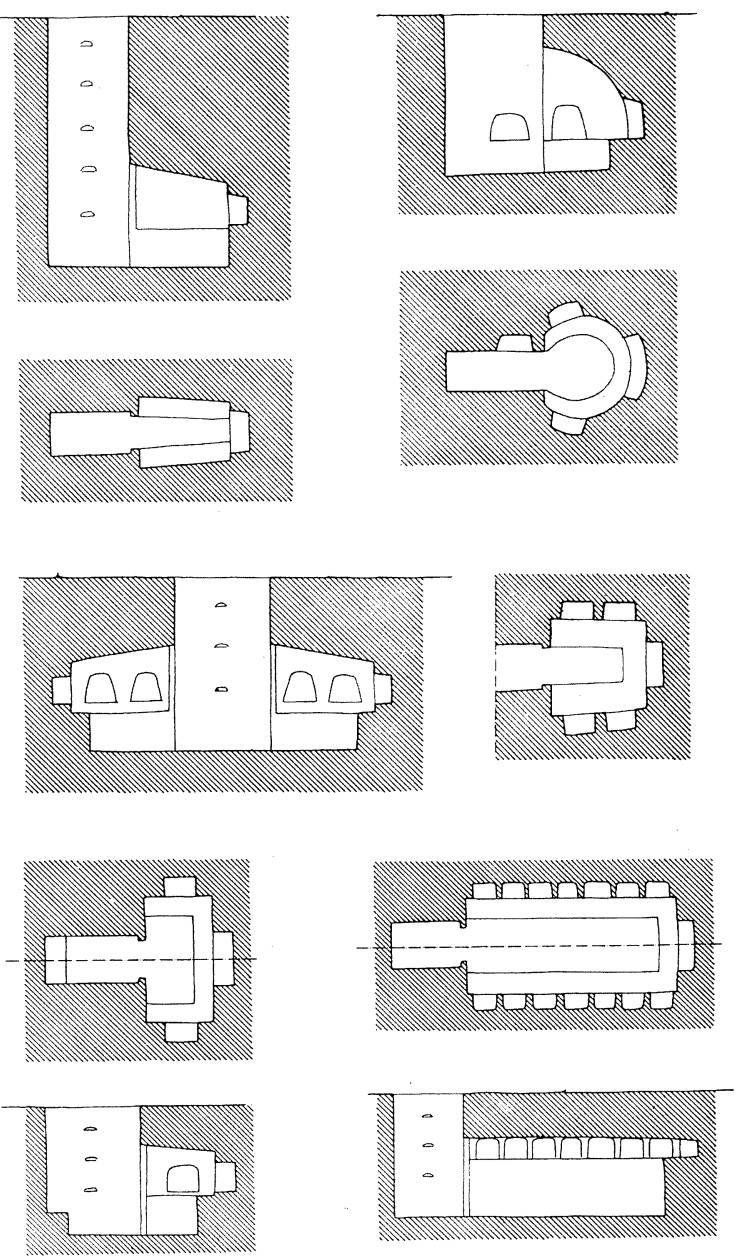

Fig. 2. Secciones verticales y horizontales de varias tumbas de cámara de Carmo (según, M. Bendala).

que muestran el apego a la tradición feniciopúnica (el cegamiento de los pozos por colmatación tras los sepelios), o el no seguimiento de rituales y fórmulas romanas (como sugiere la ausencia generalizada de monedas) - y otros datos arqueológicos, entre los que tiene no poca relevancia también la sistemática marginación del uso de cerámicas sigillatas y la preferencia por vasos de gusto tradicional ${ }^{23}$ (fig. 3).

ciada a la existencia de un posible campamento cartaginés en uso durante la Segunda Guerra Púnica (Chaves, 1990; Ferrer, 1999).

${ }^{23}$ Un fenómeno que subrayé en mi libro de 1976 (108111) y traté más por extenso en un trabajo posterior (Bendala, 1991b). Se ha comprobado en otros lugares del Imperio el apego a cerámicas de gusto local y la ausencia de la sigillata romana en contextos funerarios en que cabía, por la cronología, esperarla, hecho a explicar seguramente como rechazo a tipos cerámicos no tradicionales para su uso en la ritualidad funeraria, como se constata en necrópolis del norte de la Galia, donde no aparece sigillata hasta el último cuarto del siglo I d.C. (Tuffreau-Libre, 2000, 54) 

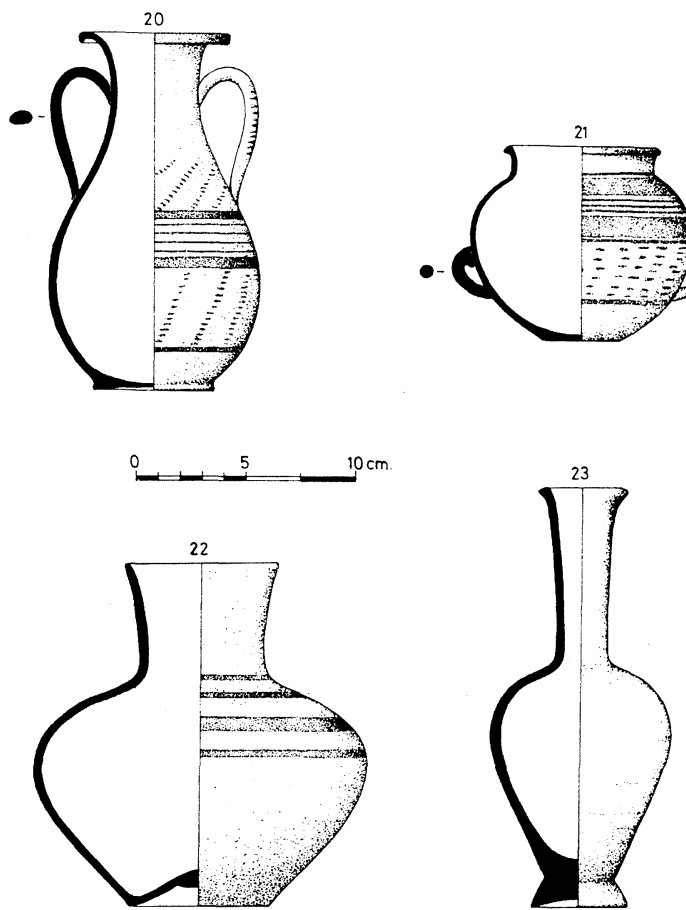

Fig. 3. Vasos de la necrópolis de Carmona, según M. Bendala.

Los fenómenos constatados en la necrópolis de Carmona - ya observados en la investigación tradicional desde J. Bonsor- se comprueban en otras ciudades béticas del mismo o parecido ambiente etnocultural ${ }^{24}$ (fig. 4 y 5). Resumí el carácter de la necrópolis carmonense en la calificación de neopúnica, una caracterización perfectamente compatible con su progresiva romanización, conclusiones que han tenido generalizada aceptación y no poca influencia en la valoración de la dinámica cultural que afectó a las culturas del Mediodía español en el seno del Imperio ${ }^{25}$. Ha habido, en torno a estas propuestas, multi-

${ }^{24}$ Con connotaciones propias de cada ciudad, en Baelo Claudia, Urso o Castulo, de lo que me ocupé ampliamente en un par de trabajos recientes, a los que remito (Bendala, 1991a y 1995), en muchas cosas con un explicable peso de lo púnico, por la pertenencia de algunas de las ciudades a su propio ámbito, y por su influencia generalizada en la Turdetania, bien constatada por Estrabón $(3,2,13)$ y comprobable en muchas otras facetas, como he argumentado en algunos estudios (Bendala, 1994, 2000 y 2001). El gusto por las urnas de cerámica de tradición local se comprueba también en una ciudad tan importante como Corduba, objeto de una refundación romana en fecha temprana, con la creación de un nuevo centro, y un proceso de romanización acentuado por su carácter de centro principal de la Bética romana. Véase sobre estas cerámicas: García Matamala, 2002 (parecen documentarse en fechas comprendidas entre el siglo I a.C. y la época julioclaudia).

${ }^{25}$ Citaré, como ejemplo significativo, la aceptación de la idea por A. Blanco en la reedición de los volúmenes corres-
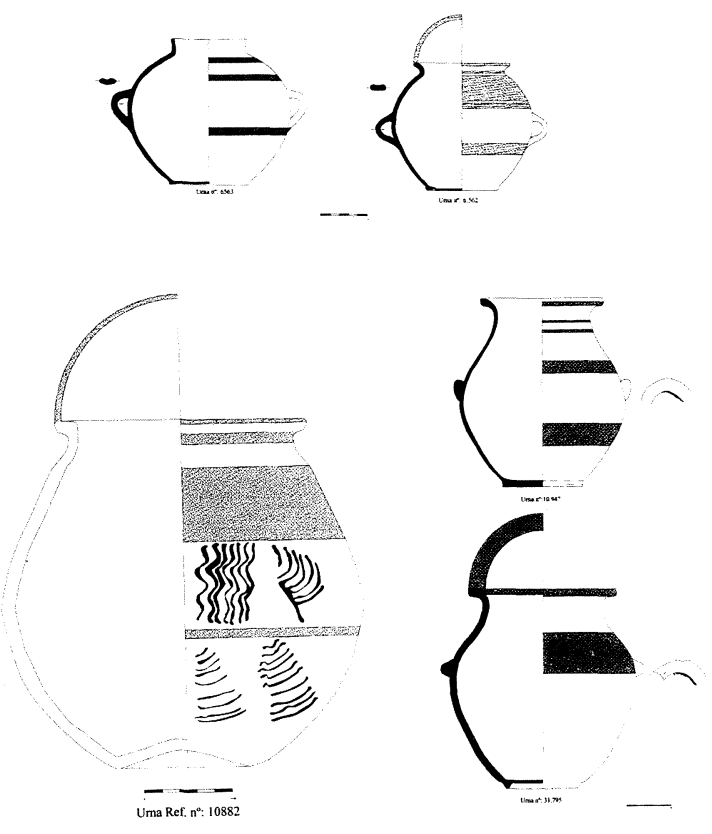

Fig. 4. Urnas de tradición indígena de las necrópolis de Corduba (según B. García Matamala).

tud de matizaciones, discusiones e incremento de datos y de ideas que han enriquecido la visión originaria ${ }^{26}$, y también excepcionales discrepancias, ejemplificables por su importancia en un reciente trabajo de G. Alföldy (2001), que vuelve a ver en Carmona, y a partir del análisis de la necrópolis, una sociedad plenamente romanizada, sin matices ni latencias a considerar del sustrato local, desde época augustea, con expresa aceptación del enunciado de Estrabón sobre la romanización de la Bética, propuestas en absoluto conciliables con el resultado general de la investigación acerca de la antigua Carmo $^{27}$ en época romana y su entorno cultural.

pondientes a Roma de la Historia de España de Menéndez Pidal (1982, 630-632), por el prestigio científico del autor y por la importancia de una obra que, como tratado general de referencia, puede tomarse como indicio fiel del estado de conocimiento de los temas que trata. La valoración como neopúnica se refuerza con el mejor conocimiento de necrópolis de parecida dinámica en sectores clásicos al efecto, como la correspondiente a la ciudad norteafricana de Sabratha, cuyas cámaras funerarias (fig. 6) y su problemática histórica y cultural reflejan fenómenos paralelos a los de la necrópolis carmonense (cf.: Bessi, 2002).

${ }^{26}$ Fundamentalmente las aportaciones de $\mathrm{M}^{\mathrm{a}}$ Belén sobre la necrópolis tradicional y la ritualidad seguida en la misma y sobre otros sectores de enterramientos en la ciudad antes desconocidos (Belén, 1982, 1983, 1986). Mis comentarios, en: Bendala, 1991a y 1995.

${ }^{27}$ He tenido ya ocasión de exponer por escrito mis discrepancias tanto en los presupuestos metodológicos como en los 

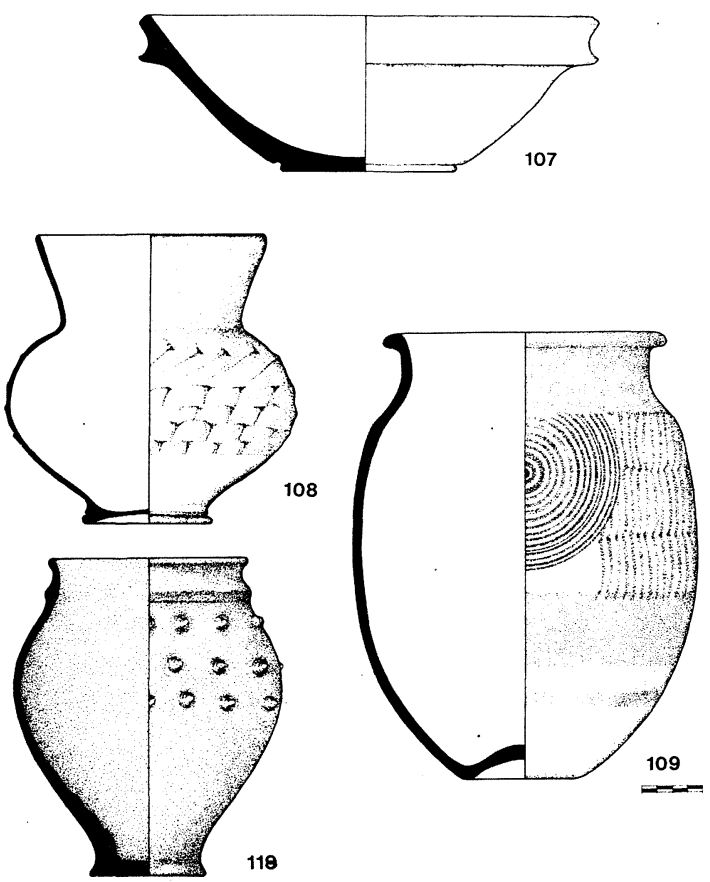

Fig. 5. Ajuar de una tumba de Cástulo (Linares, Jaén), según A. Canto y J. Urruela.

Los datos de la necrópolis están en línea con lo expresado por Estrabón en lo que hace a la latinización, aunque junto al uso del latín se compruebe la permanencia, por ejemplo, de nombres nativos y de sistemas onomásticos no romanos. Aparte de lo discutible que puedan ser la lectura y la raigambre púnica o no del nombre Urbanival escrito en una de las urnas carmonenses (fig. 7), las alternativas propuestas, últimamente por G. Alföldy (2001, 384), y las argumentaciones en el mismo sentido de $\mathrm{A}$. Caballos $(2001,14)$, no me parecen que cierren definitivamente la cuestión ${ }^{28}$; y tal vez tengamos en este y otros nombres de un sólo elemento de los documentados en la necrópolis el uso de una onomástica local - evidente en Atitta- en un ambiente inicialmente peregrino, con creciente imposición de las fórmulas onomásticas romanas, en ocasiones por latinización de nombres indígenas, expresión de una cultura híbrida que se manifiesta apegada a las tra-

resultados en un trabajo de muy reciente publicación (2002a), al que remito para no repetirme ni alargar innecesariamente estas páginas, en las que sí entraré en aspectos no contemplados entonces.

${ }_{28}$ Entre otras cosas, la lectura Urbani Val(eriorum) no la creo avalada en una interpunción entre Urbani y val que, aunque se dice comprobada en el examen del letrero (Alföldy, 2001,384 , nota 15 ), no me parece que exista realmente (tampoco la vió, ni la plasmó en sus dibujos, el muy observador J. Bonsor: cf. Rada y Delgado, 1885, lám. XVII y XXIV)
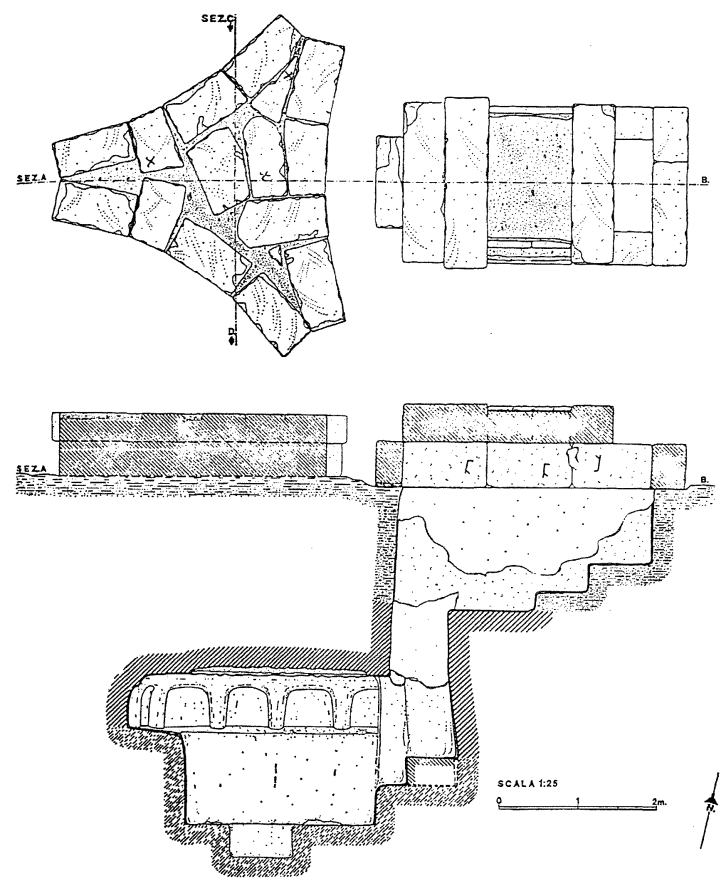

Fig. 6. Planta y secciones de una tumba de la necrópolis de Sabratha (según di Vita-Brecciaroli Taborelli).

diciones locales en una cosas y abierta a las novedades de la romanización en otras ${ }^{29}$.

Los cambios en la cultura de los carmonenses en línea con una innegable romanización hubieron de ser paulatinos, aunque no existen datos, ni hay que suponerlos frente a toda evidencia, de una mutación

${ }^{29}$ Limitadamente, por la escasez generalizada de la epigrafía recuperada de la necrópolis carmonense, aflora en ella un mestizaje cultural que se advierte en mejores condiciones en otros conjuntos de ambiente cultural próximo, como la tumba familiar descubierta en 1883 en el Cortijo de las Vírgenes (en Baena, Córdoba) conocida como «sepulcro de los Pompeyos». En uso entre fines de la República y bien entrado el siglo i d.C., contenía una docena de urnas con inscripciones, que dan cuenta de que en la tumbas se depositaron los restos de individuos que llevan, unos, nombres indígenas, seguramente turdetanos (Aninna, Ildrons, Igalchis, Velgana y otros; alguno, por la filiación, remite al nombre púnico, Hannón, del padre); otros, nombres romanos, como los Pompeyos (un amplio comentario, en: Rodríguez Oliva, 1998, 320-322 y 2002, 270-273). Este y otros casos recuerdan la extensión de los nombres romanos entre las poblaciones indígenas como consecuencia de las relaciones de patronazgo y clientela entre colonizadores y colonizados, partícipes de sistemas de relación social en buena parte confluyentes, que facilitaron la integración de comunidades hispanas en los sistemas clientelares romanos y la proliferación de una onomástica latina que traducía tanto las estructuras sociales autóctonas (mayoritariamente, en época republicana, los individuos con tria nomina mantenían su estatuto peregrino) como los sistemas de acción colonial (cf.: González Román, 2001, 180 y passim). Sin olvidar los fenómenos de «traducción» al latín de la onomástica indígena o feniciopúnica, como se recordó en nota 15. 


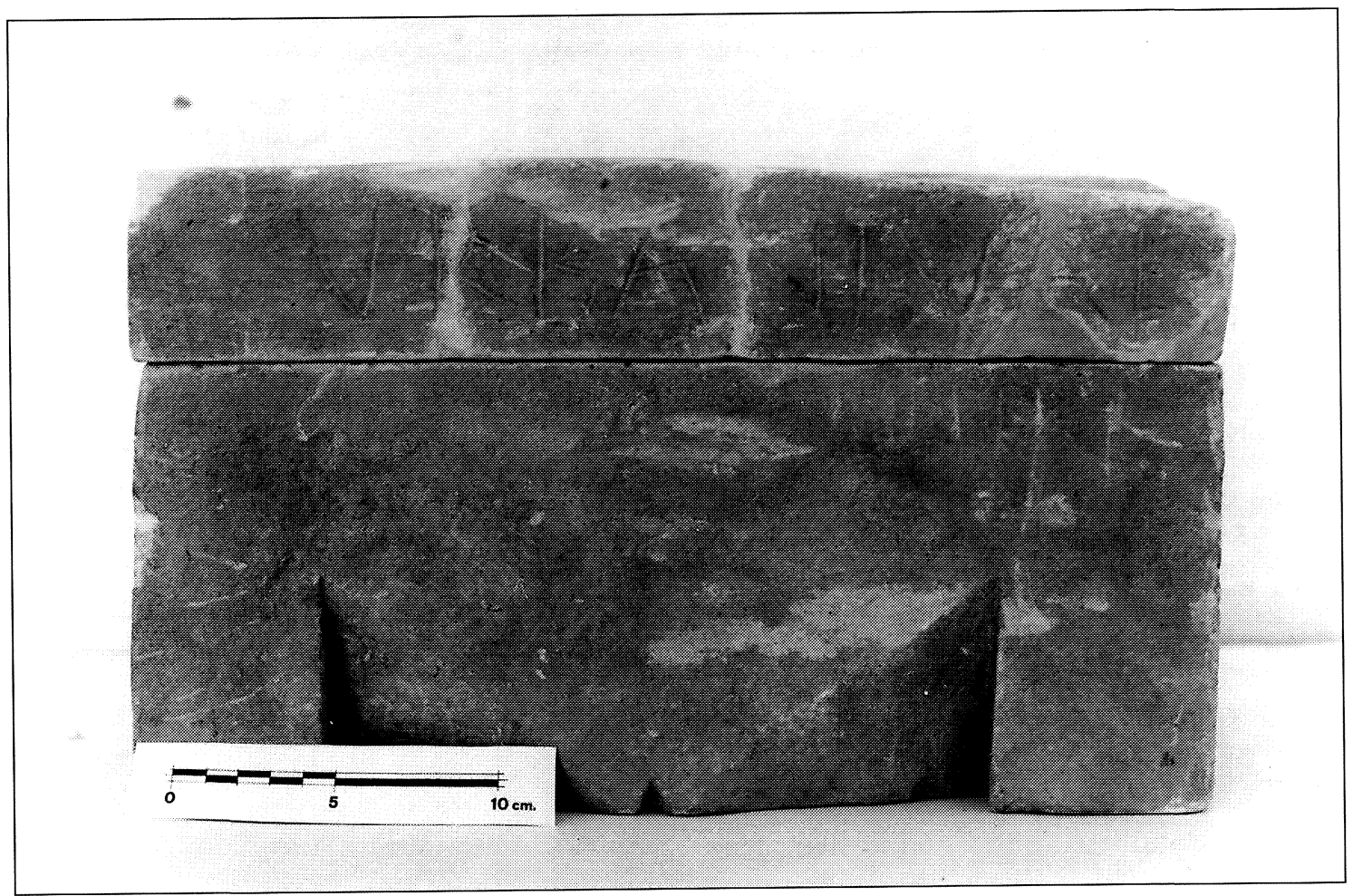

Fig. 7. Urna de la necrópolis carmonense, con el letrero URBANIVAL en la tapadera. Fotografía de 1974 de M. Bendala.

que supusiera una desaparición tan radical de las estructuras organizativas, sociales y culturales propias ya en época de Augusto. Las manifestaciones arqueológicas revelan fenómenos de distintos niveles de integración o de transformación, en función de los distintos planos en que se desenvolvía una comunidad urbana antigua como Carmo en el seno del Imperio. Una faceta tan importante como la correspondiente a los sistemas de parcelación y de propiedad territorial, con su lógica correspondencia en la organización social y sus élites dirigentes, se muestra en Carmona largamente apegada a la tradición prerromana, vigente aún en época flavia, como parece demostrar una importante inscripción carmonense perdida y transmitida por Cándido María Trigueros, que Hübner tuvo por falsa, pero que la investigación moderna tiende a demostrar con sólidos argumentos que no lo es (un detenido estudio: Chic García, 2001). De época seguramente flavia, da cuenta de una organización del campo en centuriae que aún mantenían su nombre indígena-Aibores, Volces, Agtes, Ligyes - , propias de un sistema de organización local documentado para otras ciudades béticas en la misma inscripción y en otras de la región, todo ello en el marco de una tradición en los usos agrícolas y en los repartos de la tierra que per- duraron largo tiempo en la Betica romana ${ }^{30}$. La integración en el Imperio se haría a partir de una aceptación de esa realidad en el marco de la nueva realidad hispanorromana, con cambios que pueden percibirse unas veces y no otras, que podían suponer incluso una readaptación de concepciones romanas para acomodarlas a las realidades locales ${ }^{31}$.

${ }^{30}$ Una cuestión ampliamente tratada por P. Sáez, 1978, 1998 , entre otros trabajos. En el segundo, a partir de los datos disponibles en torno a los sistemas de propiedad y otros concernientes al mundo agrario, empieza por cuestionar como tantos - la concepción de la «romanización» tal como la ha ido consagrando la historiografía tradicional.

31 Que es lo que supone Chic al considerar que la diosa Ceres invocada en la inscripción carmonense ha de ser una diosa local de la fecundidad de larga tradición en la ciudad, a la que se acogería, en su acepción romana, como expresión de la integración en el nuevo orden social que Roma representaba, en el que la sociedad carmonense podría mostrarse en un eficaz equilibrio entre autoctonía y romanización. Dice textualmente el citado autor: «Quizás por eso la inscripción de Carmona sea más interesante, en cuanto que nos muestra a esta divinidad, que desde el punto de vista político romano ha pasado a ser secundaria, sirviendo de elemento estructurador entre dos realidades, la indígena y la romana, para las que se busca la fusión definitiva en esta época flavia en que hemos decidido fechar las inscripciones de las centuriae» (Chic, 2001, 473). Añade que a partir de esa fecha prácticamente desaparece la onomástica indígena, un síntoma más de una romanización que desde entonces se haría muy acusada. 
Quiere decirse que, en términos estructurales, Carmo aportaría su propia organización a los sistemas consolidados en el marco del Imperio, un hecho, pues, marcado por el signo de la continuidad, de la validación de realidades por otra parte dificilmente sustituibles o renunciables. Otra cosa es que en el plano urbanístico, cuya distinción del más general urbano es tan operativa según hemos subrayado en bastantes trabajos, sean claramente perceptibles cambios que, en ciudades del tipo de Carmo, se intensificarían a partir de época de Augusto hasta configurar en no mucho tiempo una de las parcelas más expresivas de la romanización. Es un fenómeno ligado a la extraordinaria importancia concedida por Roma a la creación de ambientes urbanísticos válidos como escenario arquitectónico para la vida política, a la enorme dimensión arquitectónica de su propia concepción de la ciudad, que contrastaba sensiblemente con las concepciones de la generalidad de las culturas ibéricas (últimamente: Bendala, 2002b).

Algunas ciudades hispanas, como se evidencia en Carmo en la Puerta de Sevilla, empezaron a caminar por la vía de la monumentalización arquitectónica y urbanística de signo helenístico inmediatamente antes de la incorporación al Imperio, de modo que también en ésto se hacen patentes aquí los fenómenos de continuidad; pero es una corriente que se haría notar acentuadamente en el conjunto de las ciudades, incluida la propia Carmona, en lo que también entrarían en juego las élites romano-itálicas y la adopción de esas mismas actitudes por élites locales que asumían la nueva tendencia como gesto de prestigio y acercamiento voluntario a las concepciones de la potencia dominante ${ }^{32}$. En Carmona es verdaderamente paradigmática la evolución detectada en la Puerta de Sevilla, centrada en el bastión púnico-helenístico, reformada en época republicana con el añadido de unas magníficas puertas abovedadas (fig. 8), y la construcción de un templo en su parte superior tal vez ya en época de Augusto (Jiménez, 1980). Aparte de ello, el núcleo histórico de la ciudad empieza a ser conocido en sus líneas maestras

${ }^{32}$ Es el hecho que prueban, entre otros datos, un epígrafe de La Rambla (Córdoba), del 49 a.C., que documenta la construcción por dos magistrados de la puerta de su ciudad, uno de ellos de nombre itálico - M. Coranus Alpis- y desempeñando una magistratura de tipo romano (edil), y otro de nombre indígena - Binsnes Vercellonis f(ilius)-, que desempañaba una magistratura que se tiene por indígena (decemviro): cf.: Rodríguez Neila, 1998, 255 y passim; o el de Ilipa (CIL II, 1087; CILASevilla, 300) que da cuenta de la construcción para la ciudad, y a su cargo, de una puerta con su bóveda por un personaje de onomástica claramente indígena: Urchail Attita f. Chilasurgun.

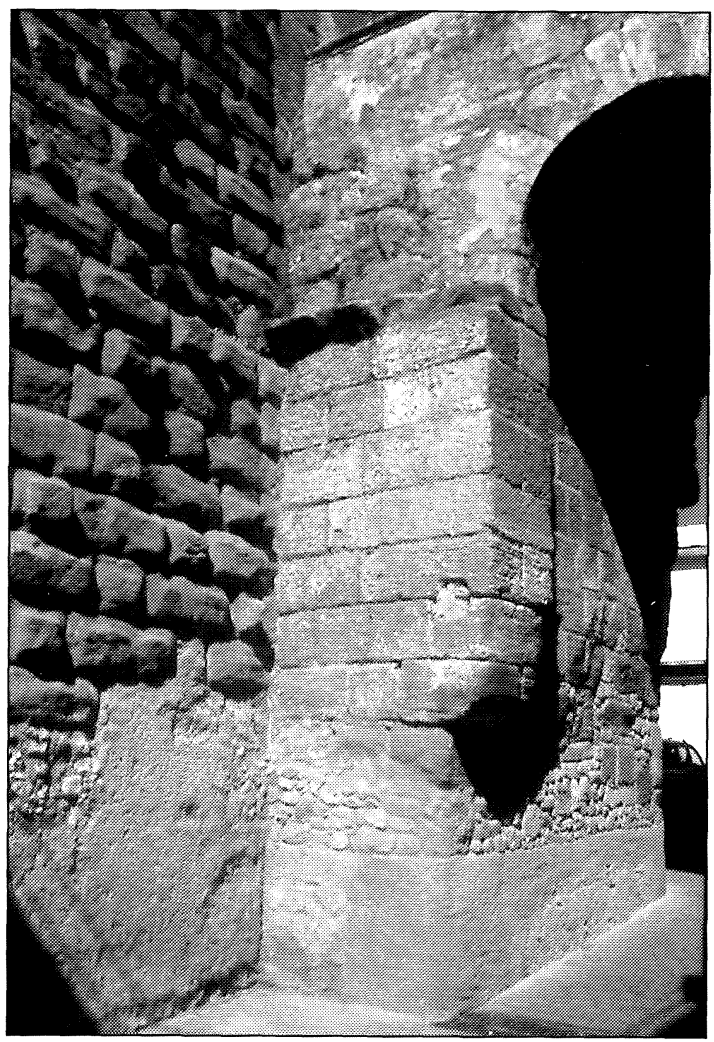

Fig. 8. Aspecto parcial de la Puerta de Sevilla, de Carmona, en el que se observa el adosamiento de las puertas abovedadas romanas al antiguo bastión púnico de sillares almohadillados (fot. J. Blánquez).

fundamentales y pueden entreverse modificaciones en época romana que empezarían por ser una ampliación al sector situado al sureste de la vía fosilizada después en lo que impropiamente suele denominarse cardo maximus de la ciudad (que une las Puertas de Sevilla y de Córdoba), modificaciones progresivas, con introducción de edificios a la romana sobre todo a partir de época de Augusto ${ }^{33}$, y una unificación del gran núcleo urbano, extendido ya a la totalidad de la península del Alcor, con la construcción de un importante conjunto foral - que incluía un gran templo de mármol- hacia el centro del mismo, a partir de época julio-claudia, en un punto que sutura la zona del norte más intensamente ocupada en los tiempos prerromanos con el área de expansión romana (Belén et alii, 1996; Belén y Lineros, 2001; Beltrán Fortés, 2001; Márquez Moreno, 2001).

${ }^{33}$ En que se construyó, como un verdadero arco triunfal, la monumental Puerta de Córdoba, referencia paisajística importantísima a partir de entonces en la vieja arteria que desde ahora se conocería como Via Augusta (Ojeda Calvo, 2001). 
La renovación urbanística se hacía eco sensible de las necesidades o voluntades de integración en el Imperio, pero debía de seguir siendo importante también la integración en la propia ciudad, la autoafirmación como carmonenses, y es a esa necesidad a la que podían servir las tradiciones funerarias de sabor local, expresión de la cohesión de la comunidad, que por fenómenos de recreación activa de la propia etnicidad, podían no sólo mantenerse, sino acentuarse en una deliberada expresión de autoctonía. La autoafirmación como carmonense (expresada en la necrópolis) y la autoafirmación como miembro del Imperio (expresada en los centros cívicos, en el foro), no habían de ser incompatibles, sino complementarias: cada una con su dinámica, su sentido propios, y un también propio ámbito de expresión.

Es la idea que conviene destacar, al cabo de una discusión científica apoyada cada vez en más datos y propuestas interpretativas diversas: la de que una misma comunidad ciudadana puede actuar y mostrarse de manera distinta según parcelas distintas, expresión de la riqueza y la diversidad de su historia y de sus diferentes ingredientes culturales, ante lo que resulta estéril tratar de obtener diagnósticos unívocos ${ }^{34}$. Por ejemplo en lo que hace a la recurrente romanización, que pudo ser muy acusada en unas cosas y poco en otras. Y entre las que, por razones ya dichas y fácilmente entendibles, el ámbito funerario pudo ser particularmente propenso a la conservación o el subrayado de las propias tradiciones, como también se detecta en el ámbito de lo estrictamente religioso ${ }^{35}$.

${ }^{34}$ Tenemos a la mano la posibilidad de comprobarlo fehacientemente en la cercana ciudad de Baelo Claudia (Bolonia, Cádiz). De raigambre púnica, en época romana se lleva a cabo una completa renovación del centro urbano, por desplazamiento del antiguo asentamiento y la construcción de una urbe de organización y arquitectura romanas. Pero cualquiera que pudiera visitar la ciudad en pleno siglo I d.C., tras pasear por el foro, la basílica, comprar en el macellum, y maravillarse ante la considerable mole del teatro, si sale fuera, a la necrópolis, se adentraría en un paisaje en el que la estricta romanidad daba paso a un ambiente culturalmente híbrido, en el que se hacía patente la raigambre púnica de los baelonenses por la proliferación de betilos marcando el lugar de las tumbas, los «muñecos» betiliformes que personalizaban la apariencia de sus principales monumentos, y otros indicios de una personalidad cultural propia, si no es que contemplaba o participaba en ceremonias funerarias que reveleban la particular idiosincrasia de sus protagonistas (últimamente: Sillières, 1997, 200; mis comentarios, en: Bendala, 1995, 283-284).

${ }^{35}$ Cuestión en la que no es el caso entrar ahora, y que comento brevemente en Bendala, 2002a, 75 ss. Acaso convenga puntualmente recordar el hallazgo en la ciudad de un pozo o favissa con un betilo en forma de fuste de columna y testimonios añadidos de lo que parece el seguimiento, hacia comienzos del siglo I d.C., de prácticas religiosas vinculables
Lo cual no quiere decir que las tradiciones o las expresiones funerarias fueran, como se dijo, inamovibles, y en la misma necrópolis carmonense se advierten claros indicios de evolución, con ingredientes de una romanización que fue impregnando también paulatinamente a los mismos ámbitos que se muestran tan apegados a las viejas tradiciones de la ciudad ${ }^{36}$, algo que ya expuse en su día, a lo que añadiré ahora algunas observaciones en la misma línea.

Es, por ejemplo, una pulsión derivada de actitudes culturales romanas la dignificación a través de la arquitectura, tal como se percibe, en los ámbitos cívicos, en ejemplos como los arriba citados. Roma había hecho, en efecto, de la arquitectura, la mejor expresión material de su capacidad demiúrgica, y en relación con ello pueden, tal vez, explicarse algunos cambios en la construcción y la configuración de las tradicionales cámaras hipogéicas carmonenses. $\mathrm{Si}$, por ejemplo, Roma construía para los teatros su propia montaña, su ladera artificial (a diferencia del griego), y pasa de la colina natural a la «montaña hueca» ${ }^{37}$, en Carmo se pasa de la cueva excavada en la roca, socavada en la naturaleza, a la cueva artificial, a una estructura que añade el prestigioso artificio de la bóveda de cañón construida con dovelas ${ }^{38}$. Es un fenómeno de «arquitectonización» de la cámara hipogéica que expresa prestigio, documentado en un conjunto de tumbas muy bien caracterizado en la necrópolis de Carmona, los «mausoleos circulares» (Bendala, 1976, 87-89), que en el mejor conser-

a las Adonías y, en conjunto, a una religiosidad atenida a tradición cultural de la ciudad prerromana (Belén y Lineros, 2001), con una propensión a los cultos betílicos de claro signo púnico rastreable en mucho ejemplos, sea en la propia necrópolis, sea en otros asentamientos, como el ya célebre santuario de Torreparedones, en la provincia de Córdoba, romanizado en algunos aspectos, pero obediente a una tipología templaria semítica y a la veneración de una imagen anicónica en forma de columna identificable con Tanit/Juno Caelestis (cf.: Cunliffe y Fernández Castro, 1999; Seco Serra, 1999).

${ }_{36}$ Obedecen a procesos que pueden sistematizarse en línea con lo propuesto por A. Fuentes (1992) para la transición entre las prácticas funerarias ibéricas y las romanizadas.

${ }_{37}$ Una expresión que tomo prestada a Alfonso Jiménez (Jiménez y Pérez Peñaranda, 1997, 13), que la usa como metáfora de una gran arquitectura, como la Catedral de Sevilla, que emula por su masividad a las alturas de la naturaleza, levantada ahora por el artificio de la mejor arquitectura, del mismo modo que era una nueva colina de Roma - equiparable en altura a la del Capitolio- el enorme teatro levantado de obra por Pompeyo en la planicie del Campo de Marte, una de las primeras grandes expresiones de una romanidad que se quería hacer tangible en su enorme poder a través de una prodigiosa arquitectura (cf. Gros, 1996, 281-282).

${ }^{38}$ Que en Carmona, con el precoz referente de la Puerta de Sevilla, se mostraba como una inicial obra que representaba el prestigio de los nuevos dominadores y una novedad técnica que cabe relacionar entre las más destacadas aportadas por la romanización (cf.: Bendala y Roldán, 1999). 

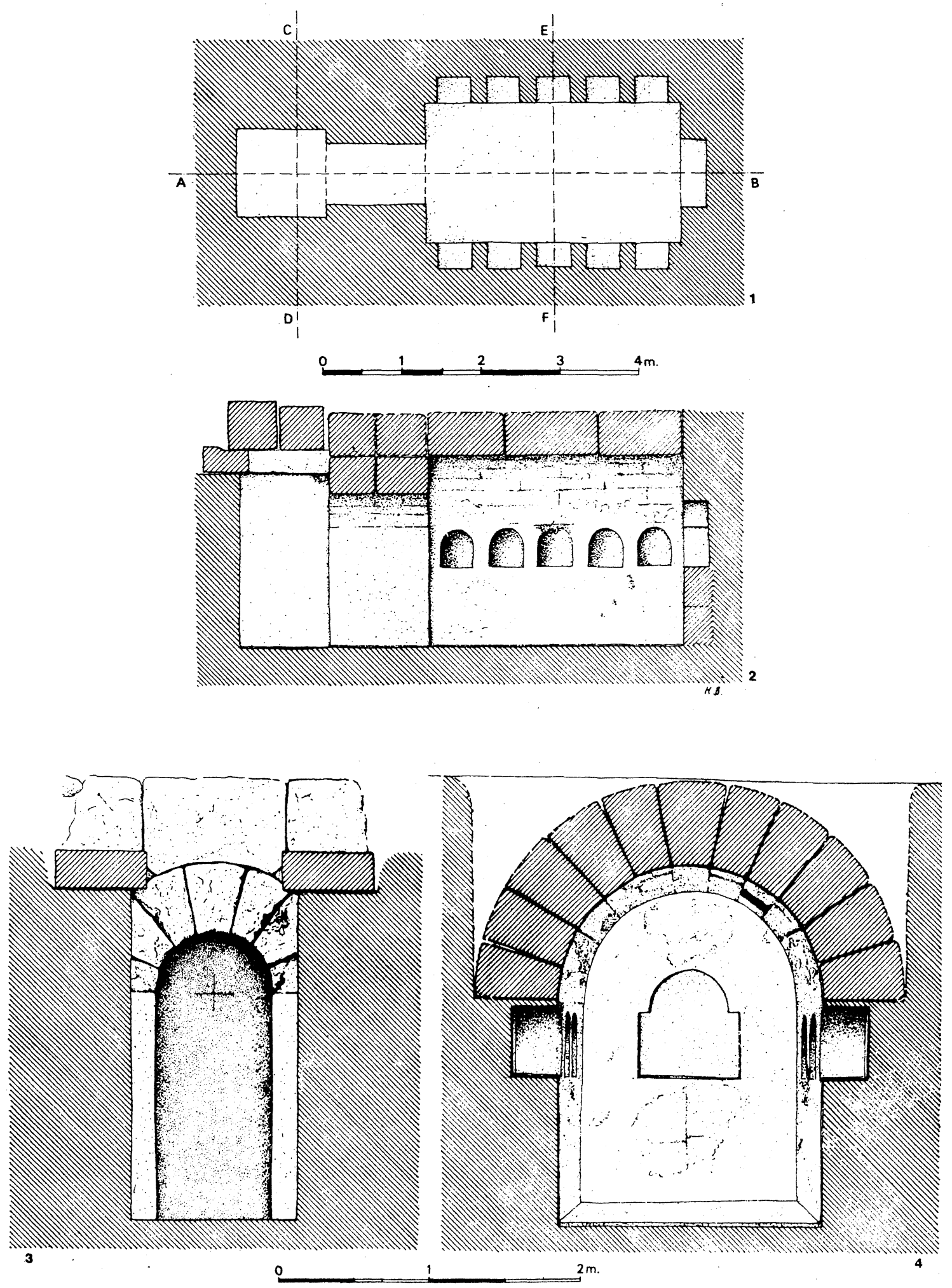

Fig. 9. Plantas y secciones de la cámara del mausoleo circular del Campo de los Olivos, de la necrópolis de Carmona (según M. Bendala). 


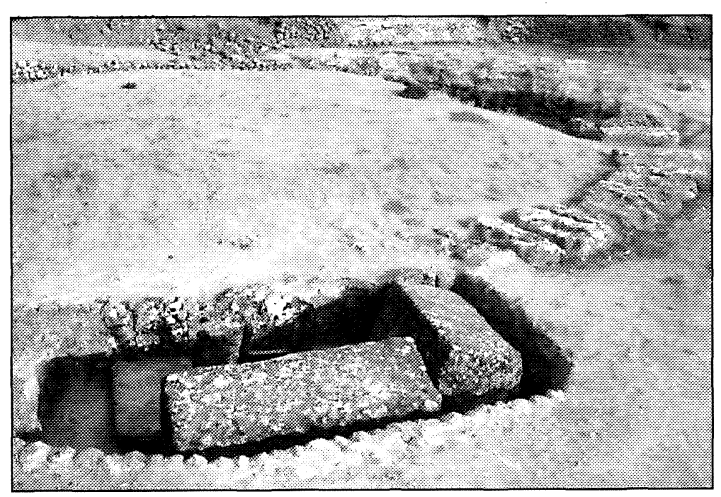

Fig. 10. Aspecto parcial de los restos conservados del mausoleo circular del Campo de los Olivos (Carmona). Obsérvense, en la boca del pozo de acceso a la cámara, los dos grandes sillares que la sellaban. Fot. M. Bendala (1974).

vado puede verse la cuidada cubrición abovedada de la cámara (fig. 9) y una «arquitectonización» que se proyectaba también a la ritualidad funeraria, ya que del cierre del pozo por cegamiento, se pasa al cierre mediante dos grandes sillares (fig. 10) que sellaban la boca de acceso al mismo ${ }^{39}$.

Es un fenómeno que se documenta también en Corduba, donde se han hallado tumbas de cámara, seguramente hipogéicas (fig. 12), con bóvedas construidas para su cubrición, que recuerdan tipológicamente a tumbas como las carmonenses de cámara y patio exterior excavado profundamente en la roca, como la tumba de Postumio (fig. 13), o en una ladera, como la de Prepusa ${ }^{40}$ (figs. 14 y 15). Acerca del

39 Una tendencia rastreable en otras tumbas de la misma necrópolis que buscan una disposición más monumental, como muestra la también significativa disposición de la cámara y su acceso en el llamado «mausoleo cuadrangular» (Bendala, 1976, 86): se accede a la cámara por un profundo y estrecho pozo con escalera (fig. 11), cubierto a la altura del suelo exterior por losas de piedra en las que se abre un pequeño hueco cuadrado para las entradas y salidas, hueco con una entalladura exterior para facilitar el sellado con otra losa; también se deja entre las losas un pequeño agujero abocinado destinado, seguramente, a la práctica de la profusio, tal vez una expresión más de acercamiento a las tradiciones funerarias romanas. Hago referencia, a este caso, a la insistencia en dotarse de tubos de libación en las tumbas ya plenamente romanas, del siglo II d.C., halladas en la necrópolis junto a la puerta norte de la ciudad (Belén et alii, 1986).

${ }^{40}$ Cf. Bendala, 1976, 82-84. Como pudo deducirse mejor tras la primera publicación de la necrópolis, esta tipología monumental puede explicarse por ampliación del pozo originario en la forma habitual de las cámaras carmonenses, una ampliación y monumentalización que tiene también precedentes en ambientes púnicos, como en la necrópolis de Puente de Noy, en Almuñécar (Granada), donde también se procedía, dada la anorme amplitud del gran pozo excavado, a cerrar arquitectónicamente la puerta mediante sillares, que, cuando la tumba fue excavada, aún conservaban líneas de pintura para facilitar, en cada remoción por un nuevo sepelio, la recolocación de las piedras en su posición originaria (cf.: Bendala, 1995, 279-280).

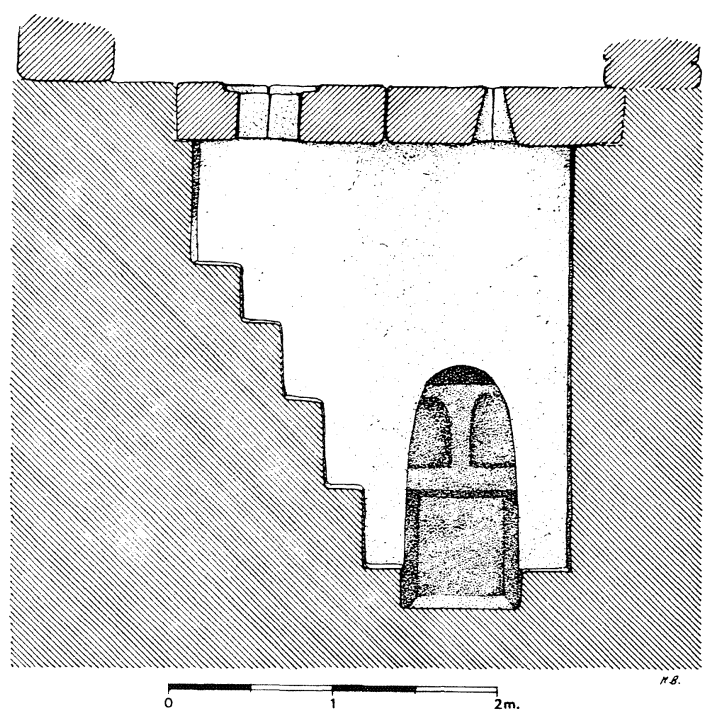

Fig. 11. Sección vertical del pozo-escalera de acceso a la cámara funeraria del llamado mausoleo cuadrangular (Carmona). Según M. Bendala.

paralelismo formal con las tumbas carmonenses (propuesto en el estudio de las tumbas por Vaquerizo, 2001, 137 ss., y 2002, 182 ss.), es difícil pronunciarse sobre si existe una vinculación que adscriba las tumbas cordubenses a una tipología de raigambre más local que estrictamente romana, de modo que tendríamos en éstas una magnífica expresión «arquitectonizada» de aquéllas, con deliberado uso de la
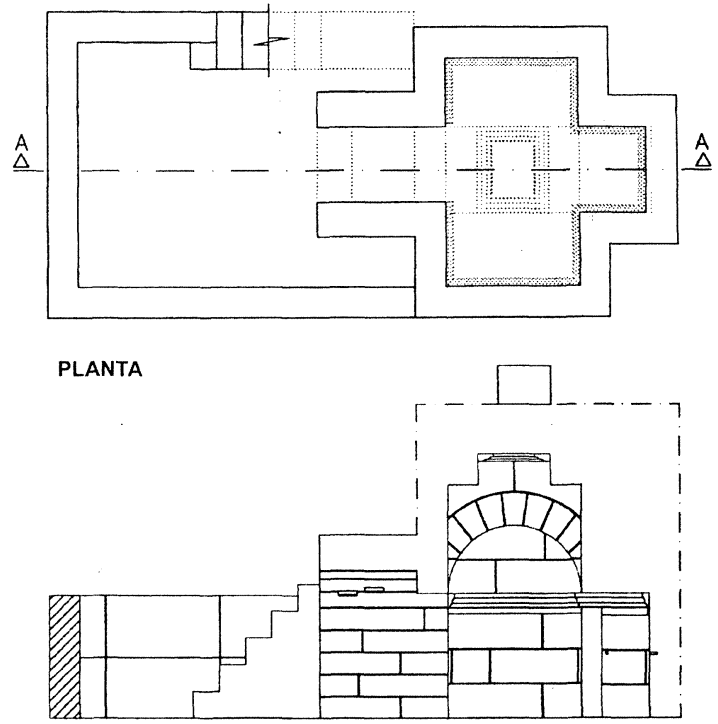

SECCION A-A

Fig. 12. Planta y sección vertical de la tumba hipogéica hallada en el Palacio de la Merced, en Córdoba (según J.L. Vaquerizo). 

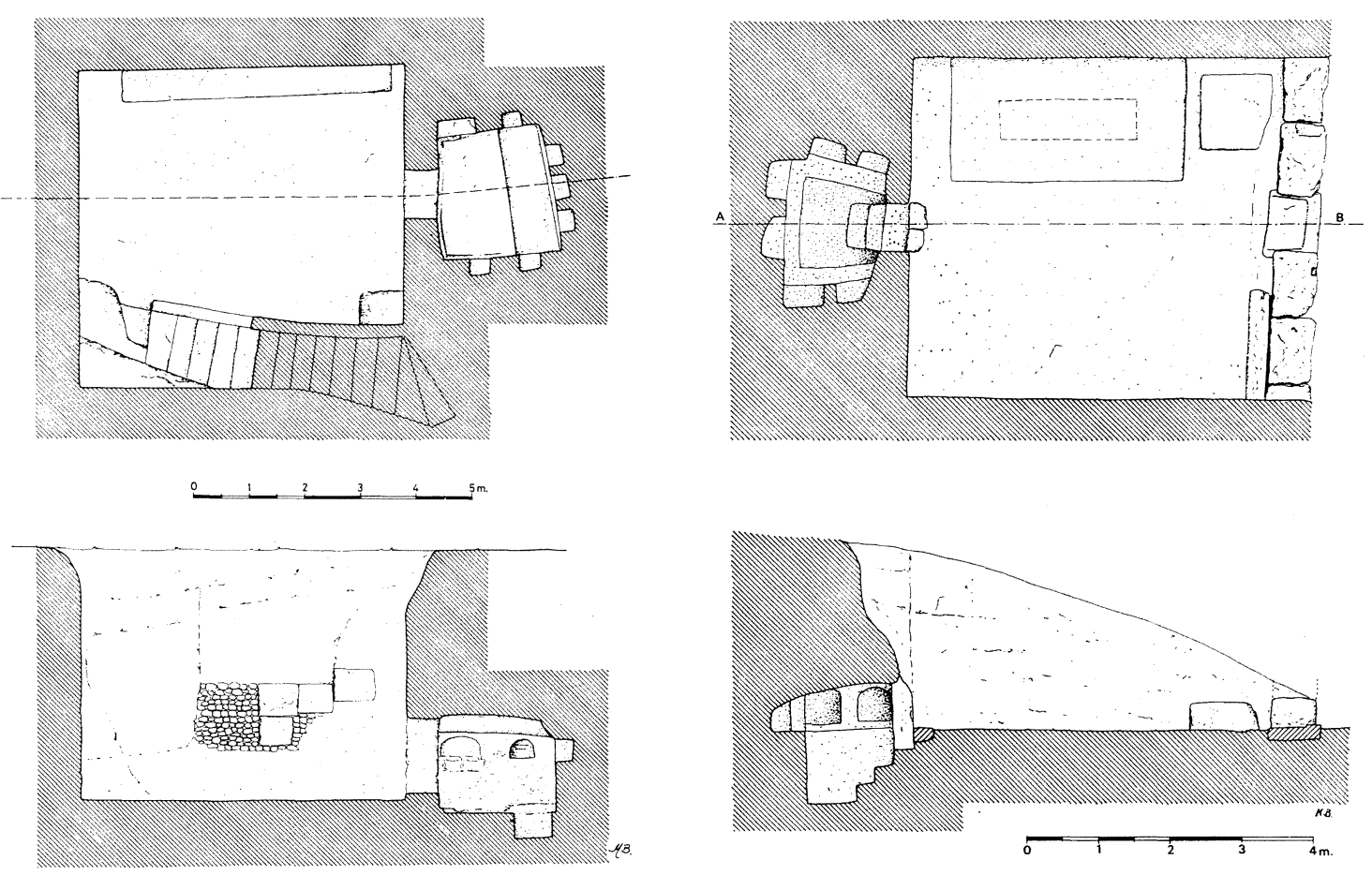

Fig. 13. Planta y sección vertical de la tumba de Postumio de la necrópolis de Carmona (según $\mathrm{M}$. Bendala).

Fig. 14. Planta y sección vertical de la tumba de Prepusa de la necrópolis de Carmona (según M. Bendala).

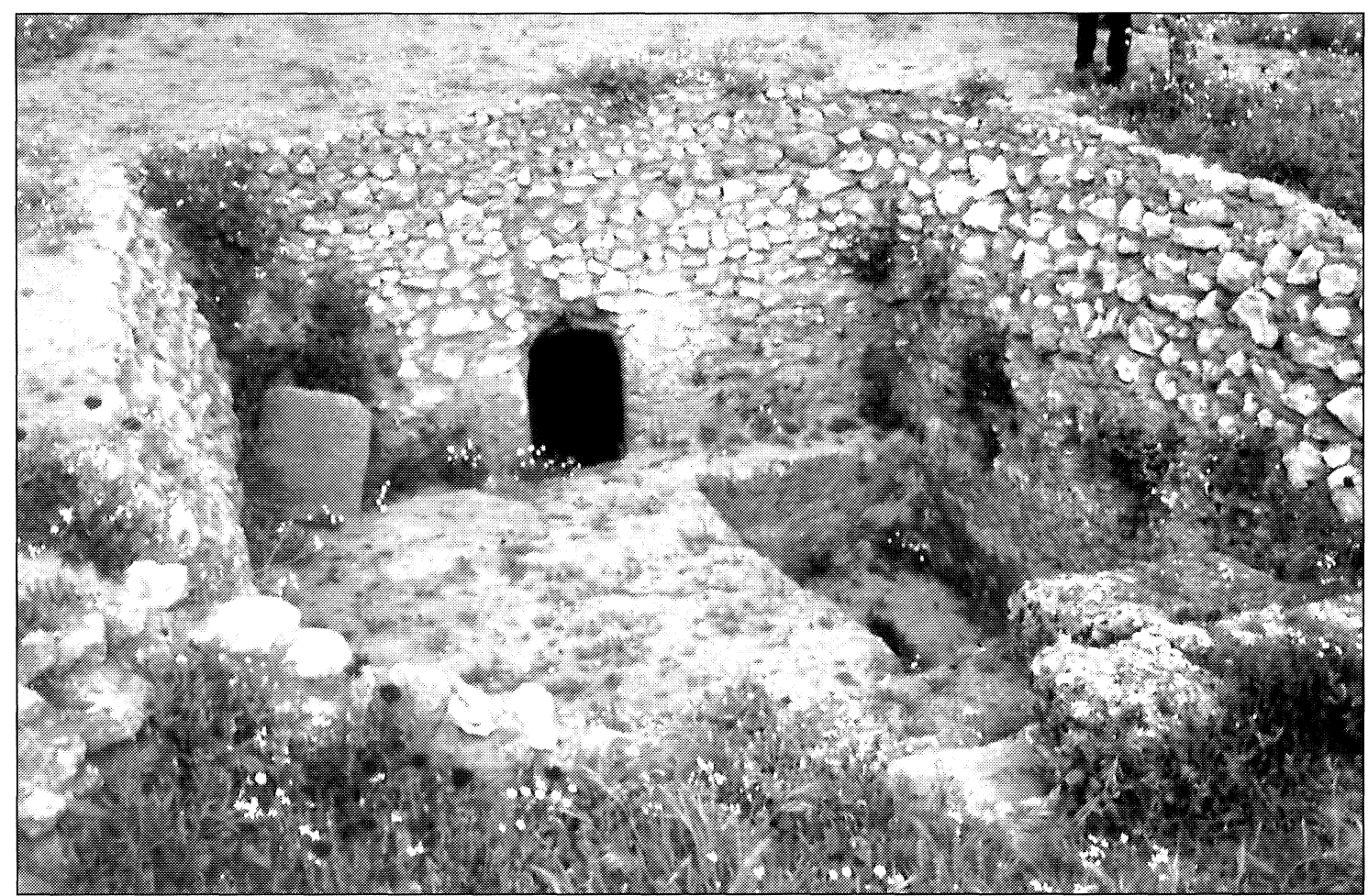

Fig. 15. La tumba de Prepusa (Carmona) en una fotografía de 1984 (M. Bendala). 


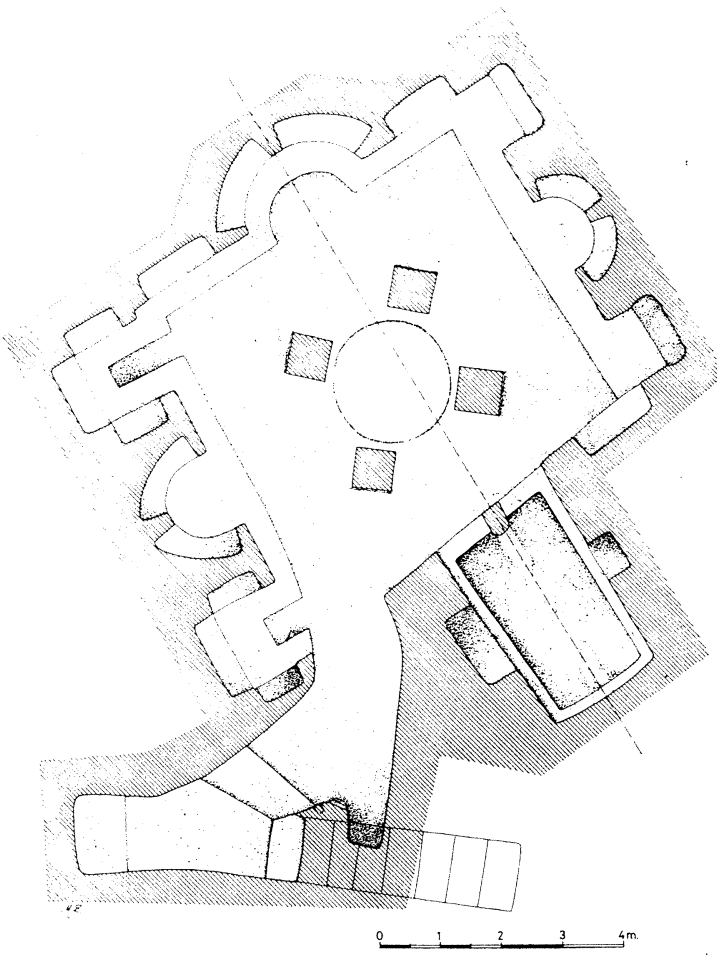

Fig. 16. Planta de la tumba de las cuatro «columnas», en Carmona. Según M. Bendala. bóveda construida como se ha comentado para otros monumentos de Carmona. Pero lo que sí puede resultar más significativo es la constatación en una de las cámaras cordubenses - la correspondiente a la calle de La Bodega, en la necrópolis septentrionalde un cierre de la puerta realizado con sillares (como pudo tener también la hallada en el Camino Viejo de Almodóvar, en la necrópolis occidental) que sí puede remitir a tradiciones más locales que romanas, en línea con las peculiaridades constatadas en Carmona. Nuevos datos, y mejores circunstancias en la documentación originaria de las tumbas, podrán afinar en estas clase de apreciaciones (de gran valor indiciario, por otra parte).

Es evidente, en la misma línea, la romanización de una cámara funeraria carmonense como la de la llamada tumba de las cuatro «columnas» (Bendala, 1976, 84-85), que reproduce en pequeño una casa de atrio con los cubicula u otras dependencias atrofiados en pequeños nichos o cámaras de poca profundidad (fig. 16); o lo que, en idéntica dirección, representa la monumental tumba de Servilia (Bendala, 1976, 73-79), en este caso atribuible a la aristocracia funcionarial romana de la ciudad, que reproduce una mansión señorial de corte helenístico; destaca por sus valores significativos y escenográficos el gran patio porticado como elemento central (fig. 17), en

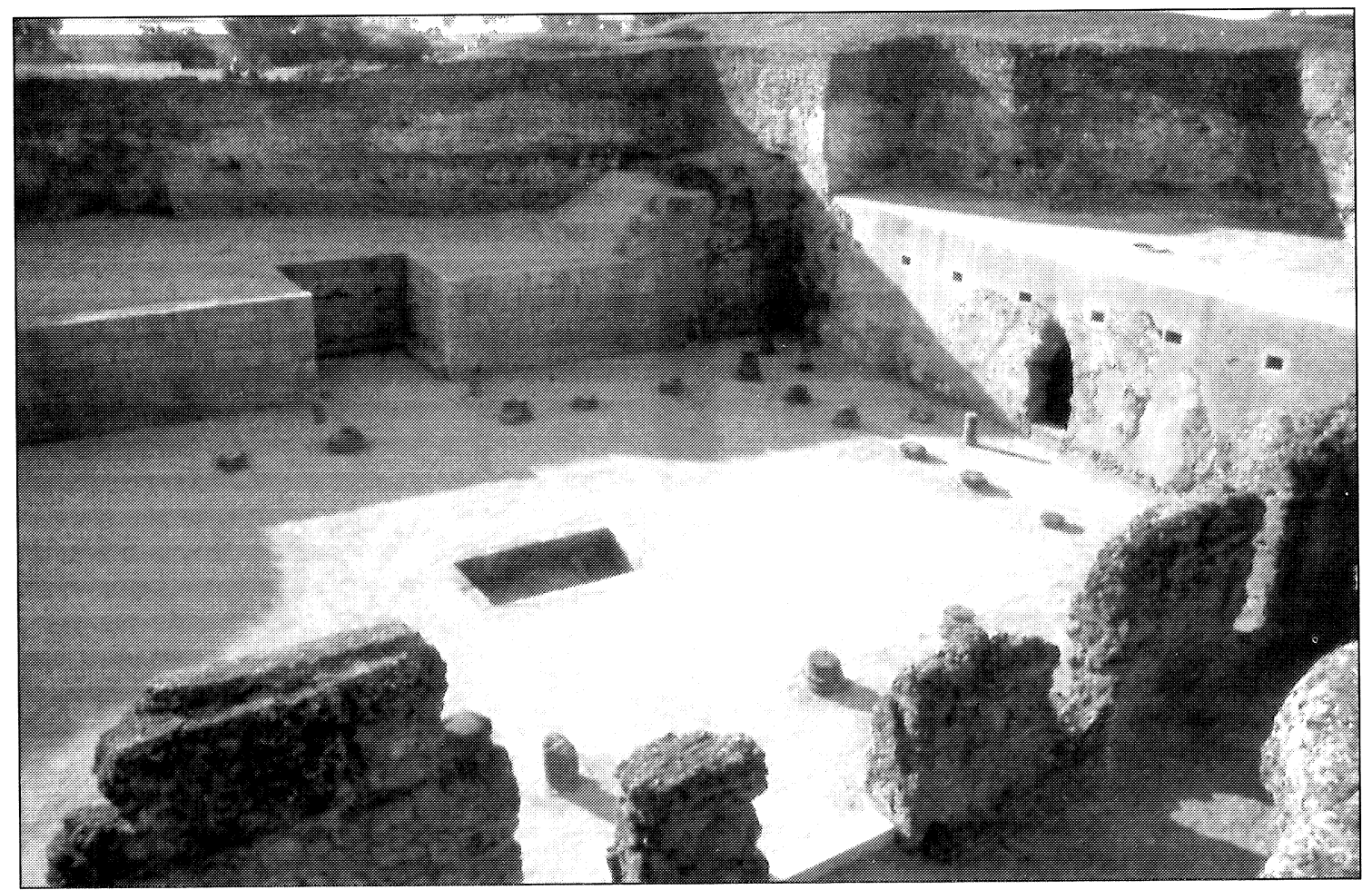

Fig. 17. Estado actual del patio central de la tumba de Servilia, en la necrópolis de Carmona. Fot. M. Bendala. 
torno al que, como en el caso anterior, se alinean unas pocas estancias, que son como la atrofia de las domésticas, aunque reservando una particular atención a la rara cámara cupuliforme que antecede a la funeraria, explicable quizá por su relación con la parte superior, donde quizá se celebraban los banquetes funerarios, de modo que se podrían realizar profusiones dedicadas a los difuntos, a través del óculo de la antecámara cupuliforme ${ }^{41}$ (una versión más aparatosa de lo que quizá tenía lugar en el mausoleo cuadrangular).

La importancia del banquete se hace evidente en una importante tumba de Carmona, el «Columbariotriclinio», que puede ser tomado por una de las más relevantes expresiones de romanización sociológica y ritual en la sociedad carmonense que se muestra en los monumentos de la necrópolis (Bendala, 1976, 81-83). Se trata de un verdadero columbario, que debía de estar destinado a los miembros de un collegium funeraticium, en el que la importancia de los banquetes se hace evidente por la concedida al amplio triclinio que se constituye en elemento principal de la disposición de la tumba (fig. 18). Hay que suponer una enfatización de la celebración de banquetes a la romana, con la típica disposición del comedor con lechos, que representa toda una escenificación de la clase de sociedad que la romanidad comportaba, y que tenía por modelos a seguir las costumbres de las élites urbanas. La importancia social del banquete en la sociedad romana, sobre todo como encuentro entre los notables, escenificación y teatralización de sus virtudes cívicas, tuvo una especial repercusión en la Bética (del Hoyo, 1993; Rodríguez Neila, 2002, 364 ss.) y no sería de extrañar que la ritualidad social del banquete, con una explicable proyección en el mundo funerario, fuera tenida por una expresión de acercamiento a las prácticas de una sociedad romana que iba convirtiéndose, por la fuerza de los acontecimientos, en referencia incuestionable de liderazgo cultural y de progreso social ${ }^{42}$.

Sin embargo, no se observan en la necrópolis de Carmona cambios sustantivos en el paisaje funerario o efectos claros de romanización en la generali-

${ }^{4}$ Así lo sugerí en su día y ha sido puesto en duda después en un trabajo que aporta datos de interés sobre la estructura de la tumba y su relación con las canteras de la ciudad (Rodríguez Hidalgo, 2001, 195-196), aunque -sin poder asegurarlo con datos firmes- me ratificaría en una idea que puede tener que ver con la predilección por una ritualidad que enfatizaba la importancia del banquete y la profusio, introducidos o fortalecidos en Carmona en virtud, tal vez, de la progresiva romanización de las costumbres funerarias, como ahora se dirá

${ }^{42}$ Sería una cuestión a tratar con más reposo en otro momento, acopiando con detalle toda la información disponible, para así robustecer la hipótesis o descartarla. dad de la tipología monumental. Pese a que se ha perdido mucho de la apariencia exterior de las tumbas, se barrunta una escasa proyección exterior de las mismas, de modo que se configuraría una necrópolis con una disposición que más parece recordar la propia de cementerios del tipo de los feniciopúnicos de Puig des Molins u otros del mismo o cercano círculo cultural. No se perciben ordenaciones en «Gräberstrassen», o calles funerarias, tan características de las necrópolis romanas (von Hesberg, 1992, 26 ss.), que se detectan, por ejemplo, en Corduba, y no digamos en Augusta Emerita y demás ciudades romanas. Acaso se percibe cierta ordenación en algunas de las tumbas más romanizadas, como los mausoleos circulares, en el Campo de las Canteras, una de las zonas más alejadas de la necrópolis respecto de la ciudad ${ }^{43}$. Y tampoco se constata en Carmona la penetración de tipos monumentales, como las tumbas en forma de altar, asociados en otras ciudades de la Bética a una temprana corriente de romanización de los ambientes funerarios (Beltrán y Baena, 1996; Beltrán, 2002; Vaquerizo, 2002).

Es verdad que se trata, en relación con esto último, de argumentos ex silentio sobre los que no cabe edificar hipótesis muy firmes, y habrá que realizar estudios sobre la organización general de la necrópolis carmonense y otras pesquisas para afinar la deliberación y obtener conclusiones más sólidas. Cada ciudad, además, se muestra con una personalidad diferenciada, que obliga a estudios particulares y hace cada vez más sólida la idea de que resulta muy difícil traducir esa heterogénea realidad en enunciados simples o, peor, simplistas. Carmo seguirá ofreciéndose como un extraordinario laboratorio arqueológico, histórico, para percibir con relativa fidelidad las manifestaciones de una sociedad de gran complejidad, que vivió su incorporación al Imperio según procesos y pautas de comportamiento muy diferentes, cuya captación constituye una de las más gratificantes recompensas al esfuerzo de investigar, de hacer historia. Algunas de las conclusiones obtenidas tras el conocimiento de la antigua necrópolis demuestran la existencia de otros sectores de enterramientos - junto a la puerta norte, o de la Se-

${ }^{43}$ Un posible indicio de posterioridad en el tiempo que haría más explicables los efectos de la creciente romanización. Responden, además, a una tipología monumental que, como se ha visto en Cordoba (Murillo et alii, 2002), responde a una extensión de un prototipo muy prestigiado en Roma a partir de Augusto en relación a su propio mausoleo, y resultaría muy apropiado tanto para itálicos inmigrados o individuos pertenecientes a las élites locales, que quisieran con esa elección de la tumba mostrar su adhesión a Roma y a sus máximos dirigentes. 

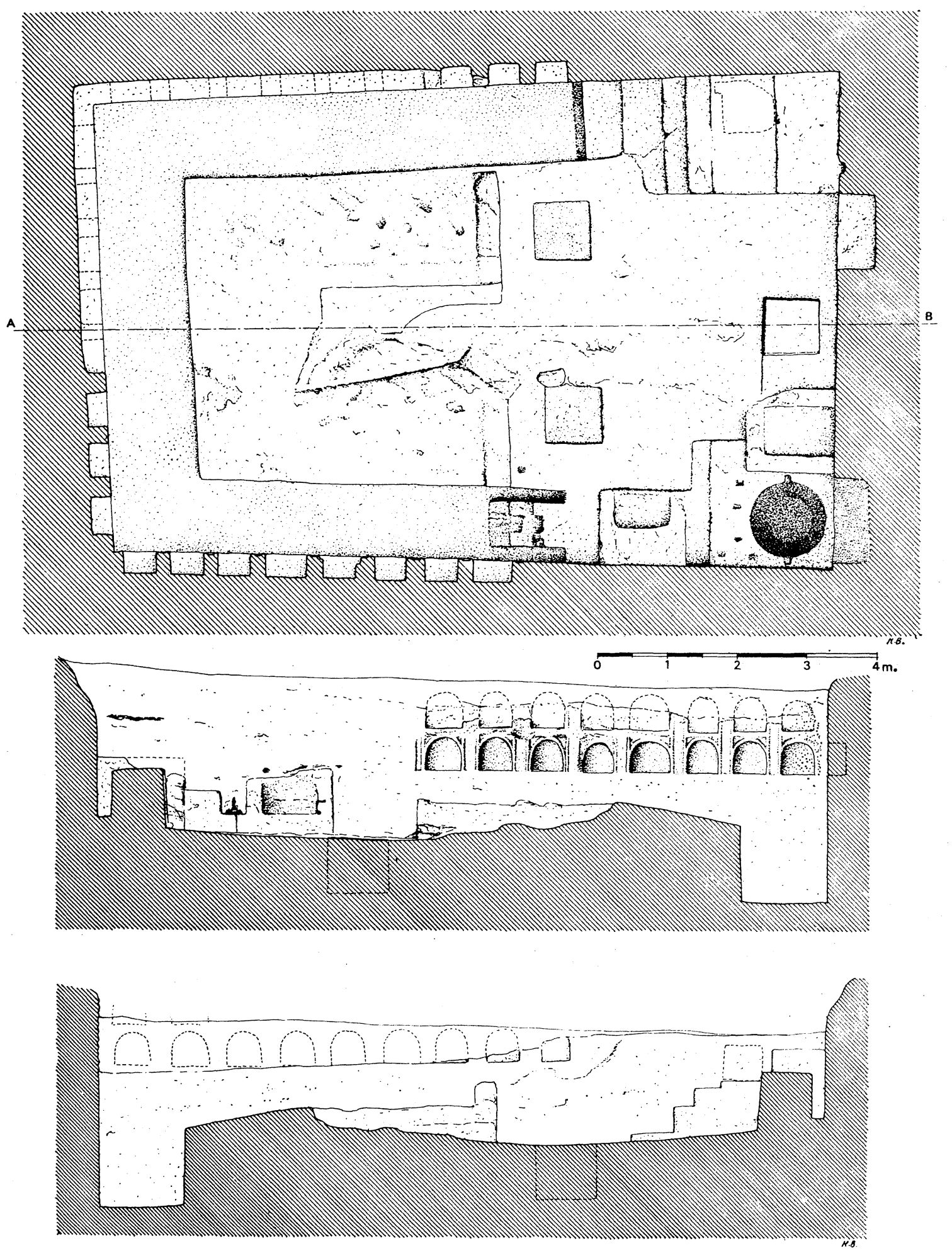

Fig. 18.- Planta y secciones del columbario-triclinio de la necrópolis de Carmona (según M. Bendala). 
dia, como antes se dijo (Belén et alii, 1986) — donde la romanización, o la romanidad de las gentes que en ellas se enterraron, se hace más patente en la presencia regular en las tumbas de una o dos monedas, seguramente el óbolo de Caronte, o en la preocupación por los tubos de libación. Pero con esos datos nos adentramos ya en el siglo II d.C., pasado mucho tiempo desde que, a partir de Augusto, el cauce de la romanización se ensanchara progresivamente, con resultados determinantes para el ambiente cultural que iría desarrollándose en Hispania en los últimos siglos del Imperio. Pero ello no significa renunciar a la captación de la diversidad cultural que, arraigada en complejos hibridismos y en la no estorbada convivencia de planos culturales distintos, dieron durante mucho tiempo en el seno del Imperio personalidad propia a las sociedades hispanas como consecuencia de su específica historia, de sus ricas tradiciones, de sus tendencias y condicionantes geohistóricos, de sus particulares tensiones sociales y culturales.

\section{BIBLIOGRAFÍA}

AlFÖLDY, G., 2002: «La sociedad del municipio de Carmo», en Caballos (ed.), 2001, 381-396.

Arce, J., 1989: «Estrabón sobre la Bética», en J. González (ed.), Estudios sobre Urso Colonia Iulia Genetiva, Sevilla, 213-222.

BelÉn DeAmos, M. ${ }^{a}, 1982$ : «Tumbas prerromanas de incineración en la necrópolis de Carmona (Sevi1la)», Homenaje a Conchita Fernández Chicarro, Madrid, 269-287.

Belén Deamos, M. a , 1983: «Aportaciones al conocimiento de los rituales funerarios en la necrópolis romana de Carmona», Homenaje al Prof. Martín Almagro Basch, Madrid, vol. III, 209-226.

BelÉN DeAmos, M. ${ }^{a}$ et alii, 1986: «Rituals funeraris a la necrópolis romana de Carmona», Cota Zero, $53 \mathrm{ss}$.

Belén, M.a.; Anglada, R.; Jiménez Hernández, A.; LINEROS, R. y RoDRíGUEZ, I., 1996: Apuntes para un centro de interpretación de la ciudad en la Casa-Palacio Marqués de las Torres, Carmona.

BELÉn, M. ${ }^{a}$ y Lineros, R., 2001: «15 años de Arqueología en Carmona», en A. Caballos, ed., 2001, 109-133.

Beltrán Fortés, J., 2001: «Arqueología de la Carmona romana: el esquema urbano», en A. Caballos, ed., 2001, 135-158.

BELTRÁN ForTÉs, J., 2002: «La arquitectura funeraria en la Hispania meridional durante los siglos II a.C. -I d.C.», en Vaquerizo (ed.), 2002, 233-258.
Beltrán Fortés, J. y Baena del AlcÁzar, L., 1996: Arqueitectura funeraria romana de la Colonia Salaria (Úbeda, jaén). Ensayo de sistematización de los monumenta funerarios altoimperiales del Alto Guadalquivir, Sevilla.

Bendala, M., 1976: La necrópolis romana de Carmona (Sevilla), Sevilla.

Bendala, M., 1981: «La etapa final de la cultura ibero-turdetana y el impacto romanizador», $L a$ baja época de la cultura ibérica, Madrid (1979), 30-48.

Bendala, M., 1987: «La cultura en la Hispania romano-republicana. Cuestiones generales», Historia General de España y América, vol. I.2, Madrid, 569-594.

Bendala, M., 1989: «La génesis de la estructura urbana en la España antigua», CuPAUAM 16, 127147.

Bendala, M., 1990: «El plan urbanístico de Augusto en Hispania: precedentes y pautas macroterritoriales», en W. Trillmich y P. Zanker (ed.), 1990, 25-42.

Bendala, M. (1991a): «Incinération et inhumation dans l'Occident aux trois premiers siècles de notre ère: le Sud de l'Espagne», en M. Vidal, ed., Incinérations et inhumations dans l'Occident romain aux trois premiers siècles de notre ère, Toulouse, 77-90.

Bendala, M. (1991b): «El banquete funerario en el mediodía hispano: una observación», en J.M ${ }^{\mathrm{a}}$. Blázquez y S. Montero (ed.), Alimenta. Estudios en homenaje al Dr. Michel Ponsich, Gerión, Anejos III, 181-186.

Bendala, M., 1994: «El influjo cartaginés en el interior de Andalucía», Cartago, Gadir, Ebusus y la influencia púnica en los territorios hispanos, VIII Jornadas de Arqueología fenicio-púnica (Ibiza, 1993), Ibiza, 59-74.

Bendala, M. (1995): «Necrópolis y ritual funerario en la Hispania altoimperial», en R. Fábregas et alii (ed.), 2000, 277-290.

Bendala, M., 1998b: «Fórmulas de promoción y desarrollo urbano y urbanístico en la Hispania tardorrepublicana», en J. Mangas, ed., Madrid, 1998, 307-312.

Bendala, M. 1999: «La ciudad en la España antigua», en F.R. García Verdugo y F. Acosta Ramírez, ed., pp. 15-36.

Bendala, M., 2000a: Tartesios, iberos y celtas. Pueblos, culturas y colonizadores de la Hispania antigua, Madrid.

Bendala, M., 2000b: «Panorama arqueológico de la Hispania púnica a partir de la época bárquida», en M$^{a}$.P. García-Bellido y L. Callegarin, (ed.), 
Los cartagineses y la monetización del mediterráneo occidental, Anejos de AEspA XXII, Madrid, 2000, 75-88.

Bendala, M. 2001: «La Carmona bárquida», en A. Caballos, ed. 2001, pp. 37-51.

Bendala, M., 2002a: «Virtus y pietas en los monumentos funerarios de la Hispania romana», en D. Vaquerizo (ed.), 2002, 67-86.

Bendala, M., 2002b: «Estructura urbana y modelos urbanísticos en la Hispania antigua: continuidad y renovación con la conquista romana», Zephyrus. En prensa.

Bendala, M.; Fernández Ochoa, C.; Fuentes, A. y ABAD, L., 1987: «Aproximación al urbanismo prerromano y a los fenómenos de transición y de potenciación tras la conquista», Los asentamientos ibéricos ante la romanización, Madrid, 121-140.

Bendala, M.; Roldán, L.; BlázQuez, J. y Martínez Lillo, S., 1994: «Proyecto Carteia: primeros resultados», Cuadernos de Prehistoria y Arqueología de la Universidad Autónoma de Madrid ( $\mathrm{Cu}$ PAUAM) 21, 81-116 (ed. en 1996).

Bendala, M. y Roldán, L., 1999: «El cambio tecnológico en la arquitectura hispanorromana: tradición, novedades y peculiaridades», II Congreso Peninsular de Arqueología (Zamora, 1996), Ed. R. de Balbín y P. Bueno, Madrid, vol. IV, 103115.

BEssi, B., 2002: «Le necropolis di Sabratha fra eredità punica e romanizzazione», en Vaquerizo (ed.), 2002, 335-352.

BlANCO, A., 1982: «Arte de la Hispania romana: arquitectura, escultura, pintura, mosáico, artes menores», en Historia de España de R. Menéndez Pidal, Madrid, vol. II, 2, 557-711.

BlánqueZ, J. y Antona, V. (ed.), 1992: Congreso de Arqueología Ibérica. Las nercrópolis, Serie Varia 1 , U.A. Madrid.

Blánquez, J.; RoldÁn, L. y Bendala, M., 2002: «La ciudad de Carteia en época púnicorromana (San Roque, Cádiz), en González Román y Padilla Arroba (ed.), 2002, 49-94.

Caballos Rufino, A. (ed.) 2001: Carmona Romana. Actas del II Congreso de Historia de Carmona, Carmona.

Caballos Rufino, A., 2001: «La paulatina integración de Carmo en la Romanidad», en A. Caballos (ed.), 3-17.

Cunliffe, B.W., 1988: Greeks, Roman and Barbarians: spheres of interaction, London.

Cunliffe, B. y Fernández Castro, M.C., 1999: The Guadajoz Project. Andalucía in the first millenium B.C. Volume I: Torreparedones and his hinterland, Oxford.
Chapman, R.; Kinnes, I. \& Randsborg, K. (ed.), 1981: The Archaeology of Death, Cambridge U.P.

Chaves Tristán, F., 1990: «Los hallazgos numismáticos y el desarrollo de la segunda guerra púnica en el sur de la Península Ibérica», Latomus, XLIX, 3, 613-622.

Chic García, G., 2001: «Religión, territorio y economía en la Carmo romana», en Caballos (ed.), 2001, 465-476.

Fábregas, R.; Pérez, F. y Fernández, C., (ed.), 1995: Arqueoloxía da Morte. Arqueoloxía da Morte na Península Ibérica desde as Orixes ata o Medievo, Xinzo de Limia.

FEAR, A.T. (1996): Rome and Baetica. Urbanization in Southern Spain c. 50 BC-AD 150, Oxford.

Fernández OchoA, C. y Morillo, A., 2002: «Romanización y asimilación cultural en el Norte peninsular. Algunas reflexiones sobre un topos historiográfico desde una perspectiva arqueológica», en A. Villa Vadés y M.A. de Blas (ed.), Poblados fortificados del Noroeste de la Península Ibérica: formación y desarrollo de la cultura castreña, Navia-Gijón, 2002.

Ferrer Albelda, E., 1999: «La olvidada 'necrópolis fenicia' de Marchena (Sevilla)», Spal, 8, 101114.

Fuentes Domínguez, A., 1992: «Las necrópolis ibéricas y su transformación ante la romanización», en Blánquez y Antona (ed.), 1992, 587- 606.

García y Bellido, A., 1967: «La latinización de Hispania», AEspA, 40, 3-29.

García Matamala, B., 2002: «Enterramientos en urnas de tradición indígena en Corduba», en Vaquerizo (ed.), 2002, vol. II, 275-296.

GonZÁlez RomÁn, C., 1994: «Control romano y resistencia indígena en los orígenes de la Bética», Actas del II Congreso de Historia de Andalucía (Córdoba, 1991), Córdoba, 131-147.

GonzÁlez Román, C., 2001: «Prosopografía y romanización de las élites: a propósito de la Hispania meridional en época republicana», en J.L. López Castro (ed.), Colonos y comerciantes en el Occidente mediterráneo, U. Almería, 171-184.

GonzÁlez Román, C., 2002: «La no ciudad en la Bética», en González Román y Padilla Arroba (ed.), 2002, 184-211.

González Román, C. y Padilla Arroba, Á., (ed.), 2002, Estudios sobre las ciudades de la Bética, Universidad de Granada.

Gros, P., 1996: L'Architecture Romaine. 1. Les monuments publics, Paris.

Haselgrove, C., 1984: «Romanisation before the conquest: Gaulish precedentes and British conse- 
quences», en T.F.C. Blagg \& A.C. King (ed.), Military and Civilian in Roman Britain, Oxford, 1-64.

Haselgrove, C., 1990: The Romanisation of Belgic Gaul: some archaeological perspectives», en $\mathrm{T}$. Blagg \& M. Millet (ed.), The Early Roman Empire in the West, Oxford, 45-71.

HESBERG, H. von, 1992: Römische Grabbauten, Darmstadt.

Hoyo, J. del, 1993: «Un aspecto socioeconómico de la Bética: los epula», Actas del I Coloquio de Historia Antigua de Andalucía, II, Córdoba, 7378.

JiMÉNEZ DíEZ, A., 2002: «Necrópolis de época republicana en el Mediodía peninsular: «Romanización» y sentimientos de identidad étnica», en Vaquerizo (ed.), 2002, vol. I, 217-232.

Jiménez Martín, A., 1989: La Puerta de Sevilla en Carmona, Sevilla.

Jiménez Martín, A. y Pérez Peñaranda, I., 1997: Cartografía de la montaña hueca. Notas sobre los planos históricos de la Catedral de Sevilla, Sevilla.

Jones, S., 1997: The Archaeology of Ethnicity. Constructing Identifies in the Past and Present, London \& New York.

KEAY, S., 1992: «The romanization of Turdetania», Oxford Journal of Archaeology, II/3, 275-315.

KEAY, S., 2001: «Romanization and the Hispaniae», en S. Keay \& N. Terrenato (ed.), Italy and the West. Comparative Issues in Romanization, Exeter, 117-144.

López Castro, J.L., 1995: Hispania poena. Los fenicios en la Hispania romana, Barcelona.

López CAStro, J.L., 2002: «Las ciudades de fundación fenicia en el Sur de Hispania: integración y pervivencias durante el Alto Imperio», en González Román y Padilla Arroba (ed.), 2002, 241 262.

Mangas, J. (ed.), 1998: Italia e Hispania en la crísis de la República romana. Actas del III Congreso Hispano-Italiano (Toledo, 1993), U.C. Madrid.

MARín DíAZ, M. ${ }^{a} A ., 2002:$ «Observaciones sobre las colonias latinas en la Hispania meridional», en González Román y Padilla Arroba (ed.), 2002, 278-287.

MÁrquez Moreno, C., 2001: «La ornamentación arquitectónica de la Carmona romana», en A. Caballos, ed., 2001, 251-262.

Morris, I., 1992: Death-Ritual and Social Structure in Classical Antiquity, Cambridge U.P.

Murillo, J.F.; Carrillo, J.R.; Moreno, M.; Ruiz, D. y VARGAS, S., 2002: «Los monumentos funera- rios de Puerta de Gallegos. Colonia Patricia Corduba», en Vaquerizo (ed.), 2002, vol. II, 247-274.

Ojeda Calvo, R., 2001: «Nuevos datos" sobre la 'Puerta de Córdoba' en época romana», en Caballos (ed.), 2002, 159-187.

Pearce, J.; Millett, M. \& Strok, M. (ed.), 2000 : Burial, Society and Context in the Roman World, Oxford.

PlácIDO, D., 1987-88: «Estrabón III: El territorio hispano, la geografía griega y el imperialismo romano», Habis 18-19, 243-256.

Rada y Delgado, J. de D., 1885: Necrópolis de Carmona, Madrid.

Rodríguez Hidalgo, J.M., 2001: «La tumba de Servilia. Nuevas aportaciones y revisión crítica», en Caballos (ed.), 2001, 189-201.

Rodríguez NeIla, J.F., 1998: «Continuidad y discontinuidad de las formas administrativas de las comunidades de la Hispania Ulterior», en Mangas (ed.), 1998, 255-270.

Rodríguez Neila, J.F., 2002: «La ciudad como 'espacio de representación' de las élites municipales en la Bética romana», en González Román y Padilla Arroba (ed.), 2002, 341-388.

Rodríguez Oliva, P., 1998: «La monumentalización de las ciudades del sur de Hispania entre la República y el Imperio», en Mangas (ed.), 1998, 313-338

Rodríguez Oliva, P., 2002: «Talleres locales de urnas cinerarias en la Prouincia Hispania Ulterior Baetica», en Vaquerizo (ed.), 2002, 259-312.

Ruiz Zapatero, G. y Chapa Brunet, T., 1990: «La Arqueología de la Muerte: perspectivas teóricometodológicas», II Simposio sobre los Celtíberos. Las necrópolis celtibéricas, Zaragoza, 357373.

SÁez Fernández, P., 1978: «Las centurias de la Bética», Habis, 9, 255-271.

SÁEz FernándeZ, P., 1998: «Transformaciones agrarias de la República al imperio en la zona meridional hispana», en Mangas (ed.), 1998, 99-106.

Seco Serra, I., 1999: «El betilo estiliforme de Torreparedones», Spal, 8, 135-158.

Sillières, P., 1997: Baelo Claudia, una ciudad romana de la Bética, Madrid.

Syme, Sir R., 1983: «Rome and the Nations», en S.R. Syme (ed.), Roman Papers, IV, Oxford, 6293.

Trías, E., 2001: Ciudad sobre ciudad. Arte, religión y ética en el cambio de milenio, Barcelona.

Tuffreau-Libre, M., 2000: «Pottery assemblages in Gallo-Roman cemeteries», en J. Pearce et alii (ed.), 2000, 52-60. 
VAquerizo, D. (ed.), 1991: Arqueología de la muerte: metodología y perspectivas actuales, Fons Mellaria (Curso de Verano, 1990), Córdoba.

VAQUERIZO, D., 2001: «Formas arquitectónicas funerarias de carácter monumental en Colonia Patricia Corduba», AEspA, 74, 131-160.
VAQUERIzO, D., (ed.), 2002: Espacios y usos funerarios en el Occidente Romano, Córdoba.

VAQUERIZO, D., 2002: «Espacio y usos funerarios en Corduba», en Vaquerizo (ed.), 2002, 143-200.

Vicent García, J.M., 1995: «Problemas teóricos de la Arqueología de la muerte. Una introducción», en Fábregas et alii (ed.), 1995, 15-31. 